\title{
VARIATIONS OF FUNCTIONAL COMMUNICATION TRAINING AND THEIR EFFECTS ON RESURGENCE
}

\author{
A Thesis \\ Presented to \\ the Faculty of the Graduate School \\ at the University of Missouri-Columbia \\ In Partial Fulfillment \\ of the Requirements for the Degree \\ Master of Science \\ by \\ BRITTANY SCHMITZ \\ Dr. SungWoo Kahng, Thesis Supervisor \\ MAY 2018
}


The undersigned, appointed by the dean of the Graduate School, have examined the thesis entitled

\title{
VARIATIONS OF FUNCTIONAL COMMUNICATION TRAINING AND THEIR EFFECTS ON RESURGENCE
}

Presented by Brittany Schmitz

a candidate for the degree of master of science

and hereby certify that, in their opinion, it is worthy of acceptance.

\author{
Dr. SungWoo Kahng \\ Dr. Casey Clay \\ Dr. Jena Randolph
}




\section{ACKNOWLEDGEMENTS}

I would like to acknowledge and thank my advisor and committee chair, Dr. SungWoo Kahng, who has supported me, not only during the course of this project, but throughout my entire Masters degree. I greatly appreciate how available he was throughout this entire process. He provided me with a wealth of knowledge and this would not have been possible without his guidance. I would also like to extend a thank you to Dr. Casey Clay and Dr. Jena Randolph for taking time out of their busy schedules to provide their expertise and serve on my thesis committee.

I would also like to thank Dr. Bethany Contreras and Savannah Tate for providing their time, support, and a tremendous amount of feedback in the early stages and throughout the development of this project. You were both crucial to this project coming to fruition.

I would like to thank the students and supervisors of the Applied Behavior Analysis program for their efforts in assisting with this research by volunteering their time to help with data collection, shift coverage, implementing with the participants, and continued moral support through this process. This would not have been possible without the efforts of the entire team.

In addition, thank you to Dr. Kahng and Dr. Casey Clay for encouraging me to be involved in research throughout the course of my graduate studies. The knowledge and experiences that I have gained from your mentorship have made me grow personally and professionally. 
TABLE OF CONTENTS

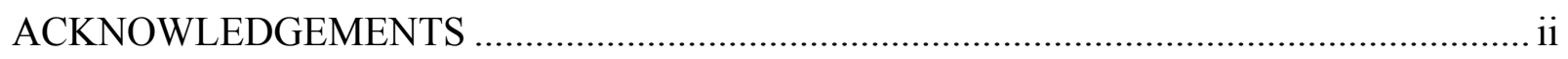

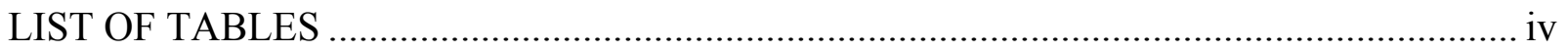

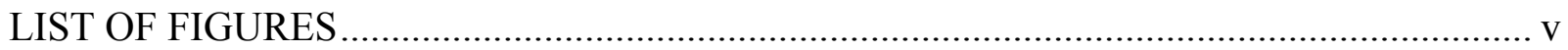

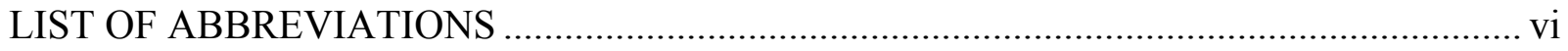

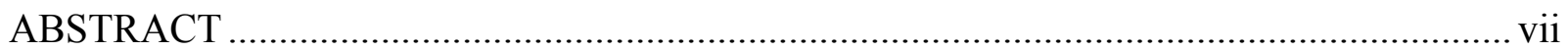

Variations of Functional Communication Training and Their Effects on Resurgence.............. 1

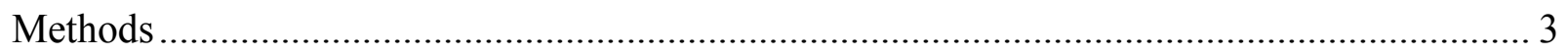

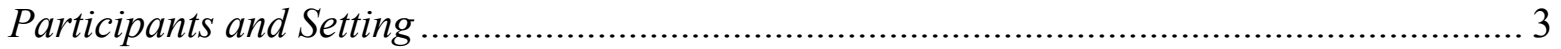

Dependent Variables and Response Measurement ...................................................... 5

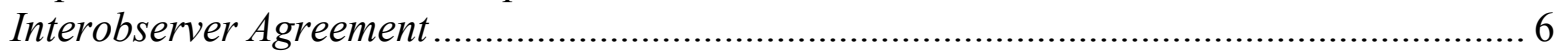

Procedural Fidelity ..................................................................................................... 7

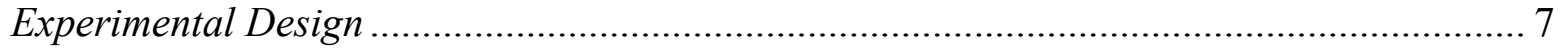

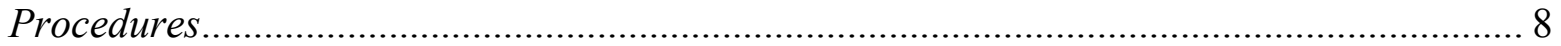

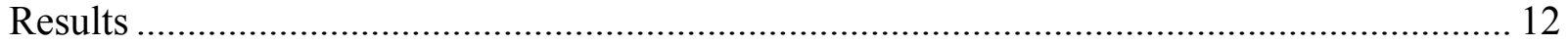

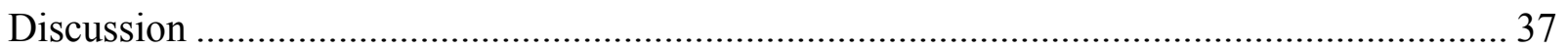

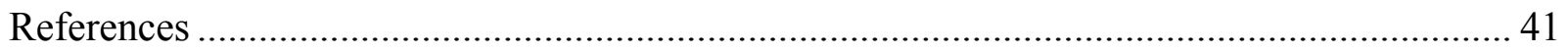




\section{LIST OF TABLES}

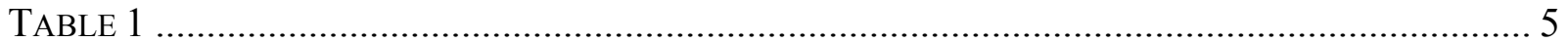

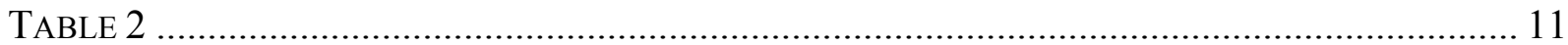

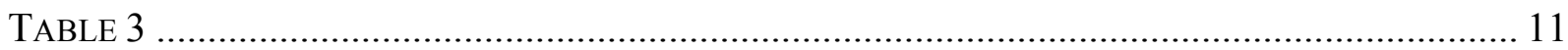




\section{LIST OF FIGURES}

FigURE 1. RESULTS OF THE FUNCTIONAL ANALYSIS FOR CRAIG DEPICTING THE RESPONSES PER MINUTE OF PROBLEM BEHAVIOR ACROSS TEST AND CONTROL CONDITIONS......

FIGURE 2. RESPONSES PER MINUTE OF PROBLEM BEHAVIOR AND FCRS FOR CRAIG................. 17

FIGURE 3. LATENCY TO PROBLEM BEHAVIOR DURING THE RESURGENCE PHASE FOLLOWING SERIAL FCT AND FCT WITH A LAG-2 SCHEDULE OF REINFORCEMENT FOR CRAIG.............. 18

FIGURE 4. MEAN PERCENTAGE OF RESPONSE ALLOCATION FOR PROBLEM BEHAVIOR AND FCRS DURING THE RESURGENCE PHASE FOLLOWING SERIAL FCT AND FCT WITH A LAG2SCHEDULE OF REINFORCEMENT FOR CRAIG. BLACK AND WHITE SEGMENTS ARE STACKED.

FIGURE 5. FREQUENCY OF FCRS IN THE RESURGENCE PHASES FOLLOWING SERIAL FCT, FCT WITH A LAG-2 SCHEDULE OF REINFORCEMENT, AND THE FIRST FOUR SESSIONS FOLLOWING THE LAG-2 SCHEDULE OF REINFORCEMENT FOR CRAIG.

FIGURE 6. RESULTS OF THE FUNCTIONAL ANALYSIS FOR RON DEPICTING THE RESPONSES PER MINUTE OF PROBLEM BEHAVIOR ACROSS TEST AND CONTROL CONDITIONS. ..................... 23

FIGURE 7. RESPONSES PER MINUTE OF PROBLEM BEHAVIOR AND FCRS FOR RON. .................... 24

FIGURE 8. LATENCY TO PROBLEM BEHAVIOR IN THE RESURGENCE PHASE FOLLOWING SERIAL FCT FOR RON. 25

FIGURE 9. MEAN PERCENTAGE OF RESPONSE ALLOCATION FOR PROBLEM BEHAVIOR AND FCRS DURING THE RESURGENCE PHASE FOLLOWING SERIAL FCT FOR RON. BLACK AND WHITE

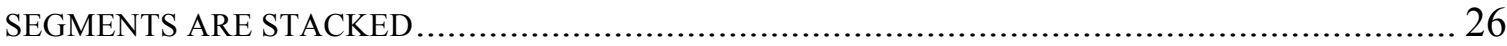

FIGURE 10. FREQUENCY OF FCRS IN THE RESURGENCE PHASE FOLLOWING SERIAL FCT FOR RON.

FIGURE 11. RESULTS OF THE FUNCTIONAL ANALYSIS FOR TOM DEPICTING THE RESPONSES PER

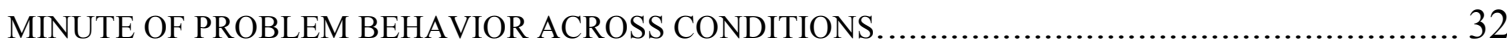

FIGURE 12. RESPONSES PER MINUTE OF PROBLEM BEHAVIOR AND FCRS FOR TOM.................. 33

FIGURE 13. LATENCY TO PROBLEM BEHAVIOR DURING THE RESURGENCE PHASE FOLLOWING SERIAL FCT AND FCT WITH A LAG-2 SCHEDULE OF REINFORCEMENT FOR TOM ................ 34

FIGURE 14. MEAN PERCENTAGE OF RESPONSE ALLOCATION FOR PROBLEM BEHAVIOR AND FCRS DURING THE RESURGENCE PHASE FOLLOWING SERIAL FCT AND FCT WITH A LAG-2 SCHEDULE OF REINFORCEMENT FOR TOM. BLACK AND WHITE SEGMENTS ARE STACKED. .. 35

FIGURE 15. FREQUENCY OF FCRS IN THE RESURGENCE PHASES FOLLOWING SERIAL FCT AND FCT WITH A LAG-2 SCHEDULE OF REINFORCEMENT FOR TOM .......................................... 36 


\section{LIST OF ABBREVIATIONS}

$\begin{array}{ll}\text { ASD } & \text { Autism Spectrum Disorder } \\ \text { ASL } & \text { American Sign Language } \\ \text { CDC } & \text { Center for Disease Control } \\ \text { EO } & \text { Establishing Operation } \\ \text { FCR } & \text { Functional Communicative Response } \\ \text { FCT } & \text { Functional Communication Training } \\ \text { FR } & \text { Fixed Ratio } \\ \text { FT } & \text { Fixed Time } \\ \text { IOA } & \text { Interobserver Agreement } \\ \text { PBx } & \text { Problem Behavior } \\ \text { RPM } & \text { Responses Per Minute } \\ \text { SGD } & \text { Speech Generated Device } \\ \text { SIB } & \text { Self-Injurious Behavior } \\ \text { Sr+ } & \text { Reinforcement }\end{array}$




\begin{abstract}
A common treatment that is implemented to decrease problem behavior and increase appropriate behavior in individuals diagnosed with autism spectrum disorder (ASD) is functional communication training (FCT; Carr \& Durand, 1985). Although demonstrated to be highly effective, it is possible that procedures will not be implemented with fidelity by caregivers in the natural environment. In these situations, functional communicative responses (FCRs) are likely to undergo extinction, increasing the likelihood of the reemergence of problem behavior (e.g., Fisher et al., 1993; Hanley, Iwata, \& Thompson, 2001), known as resurgence. In applied contexts, the resurgence of problem behavior during temporary lapses in procedural fidelity represents a reality for which there are currently few solutions (Lambert et al., 2017). One possible treatment for resurgence of problem behavior in the face of extinction challenges is multiple mand training during FCT. The purpose of this study is to evaluate what effect teaching multiple FCRs as outlined in serial FCT by Lambert, Bloom, Samaha, and Dayton (2017) has on resurgence of problem behavior and FCRs during extinction challenges. We will then evaluate what effect implementing a lag schedule of reinforcement following serial FCT will have on resurgence of problem behavior and FCRs during extinction challenges compared to serial FCT.
\end{abstract}

Keywords: functional communication training, resurgence, extinction, lag schedule, problem behavior, treatment fidelity, treatment integrity 


\section{Variations of Functional Communication Training and Their Effects on Resurgence}

According to the Centers for Disease Control and Prevention (CDC), 1 in 68 children are diagnosed with autism spectrum disorder (ASD). ASD has received an increasing amount of attention from researchers, clinicians, the media, and the general public over the past several decades. The treatment of problem behavior (e.g., aggression, property destruction, disruptions, self-injurious behavior [SIB], etc.) is one area of focus in research. A common treatment that is implemented to decrease problem behavior and increase appropriate behavior is functional communication training (FCT; Carr \& Durand, 1985). FCT is a differential reinforcement procedure in which an individual is taught an alternative, more appropriate response, which results in the delivery of the same class of reinforcer identified as maintaining problem behavior. Problem behavior is typically placed on extinction (Tiger, Hanley, \& Bruzek, 2008).

Since Carr and Durand (1985) introduced the procedure, FCT has emerged as one of the most common function-based treatment for problem behavior (Tiger, Hanley, \& Bruzek, 2008). Since then, there have been a number of manipulations to the treatment process. Tiger, Hanley, and Bruzek (2008) provided a review of the past 20 plus years of research of these variations from research to provide an empirical basis for best practices and making decisions during the implementation of FCT as a treatment for severe problem behavior.

Although FCT has been demonstrated to be a well-established and effective treatment for reducing problem behavior (Kurtz et al., 2011; Rooker, Jessel, Kurtz, \& Hagopian, 2013; Tiger, Hanley, \& Bruzek, 2008), it is possible that procedures will not be implemented with high fidelity by caregivers in the naturalistic environment. In these 
situations, the alternative responses (i.e., functional communicative responses or FCRs) are likely to contact extinction resulting in resurgence or reemergence of problem behavior (e.g., Fisher et al., 1993; Hanley, Iwata, \& Thompson, 2001). Resurgence occurs when previously extinguished responses recover after an alternative response has contacted extinction (Leitenberg, Rawson, \& Mulick, 1975). In applied contexts, the resurgence of problem behavior during temporary lapses in procedural fidelity represents a reality for which there are currently few solutions (Lambert, Bloom, Samaha, \& Dayton, 2017). One possible treatment for resurgence of problem behavior in the face of extinction challenges is multiple mand training during FCT.

Lambert et al. (2017) evaluated the effect of a serial FCT procedure (teaching multiple mands individually and only after mastery has been demonstrated with the previous FCR) on resurgence of problem behavior and the persistence of FCRs in an applied setting (participant's house and a local university clinic) to determine if serial FCT would decrease the total number of responses of problem behavior during the resurgence (extinction) test while simultaneously increasing the total number FCRs as compared to the traditional (single) FCT condition for two children. They observed more manding (use of FCRs) and a smaller percentage of total responding occupied by problem behavior during serial FCT relative to traditional FCT. However, they also observed that problem behavior occupied the largest percentage of total relapse, demonstrating a primacy effect. These results suggest that serial FCT may require modification before it can be expected to consistently produce therapeutic outcomes beyond what is already possible through a traditional FCT paradigm. Lambert et al. suggested that repeated and/or more rapid exposure to shifting contingencies might 
increase the probability of the occurrence of recency effects and the reversion of response resurgence.

One potential method to arrange for contact with shifting contingencies could be to implement a lag schedule of reinforcement. Lag schedules of reinforcement arrange contingencies that directly influence operant response variability (Lee, Sturmey, \& Fields, 2007). During a lag schedule, a response is reinforced if it differs from an indicated number of previous responses. The variability requirement is specified by the parameter of the lag schedule. For example, on a Lag 2 schedule of reinforcement, a response is reinforced if it differs from any response emitted on the previous two opportunities. A lag schedule or reinforcement following multiple mand training could potentially teach individuals to vary the use of multiple FCRs during extinction challenges.

The purpose of this study was to evaluate what effect teaching multiple FCRs as outlined in serial FCT by Lambert et al. (2017) have on resurgence of problem behavior and FCRs during extinction challenges. We then evaluated what effect implementing a lag schedule of reinforcement following serial FCT had on resurgence of problem behavior and FCRs during extinction challenges compared to serial FCT.

\section{Methods}

\section{Participants and Setting}

Three individuals diagnosed with ASD were recruited for participation in this study. All participants engaged in some form of problem behavior. Functional analyses (Iwata, Dorsey, Slifer, Bauman, \& Richman, 1982/1994; Hanley, Jin, Vanselow, \& Hanratty, 2014) were conducted in order to determine the function of problem behavior. 
Participants were able to emit a minimum of one word vocal mands or mand approximations. All sessions took place in a private therapy room at an outpatient clinic.

Craig was a 9-year-old male diagnosed with ASD referred to an outpatient clinic for assessment and treatment of aggressions. He also engaged in property destruction, disruptions, and SIB. He was able to communicate his wants and needs vocally and typically spoke using one to three word utterances. Craig was able to read short sentences with comprehension. Craig attended a public school and had a one-to-one support in the classroom. Craig's educational level was determined by the school to be at approximately the first grade level.

Ron was a 12-year-old male diagnosed with ASD referred to an outpatient clinic for assessment and treatment of aggressions. He also engaged in property destruction, yelling, elopement, and SIB. Ron occasionally expressed his wants and needs vocally with one to two word phrases and through sign, but did not consistently use the correct request for the item he was requesting. Ron attended a public school in a self-contained classroom with a one-on-one classroom support.

Tom was a 4-year-old male diagnosed with ASD referred to an outpatient early intensive behavioral intervention clinic based on reported concerns relating to deficits in communication and problem behaviors. Tom's primary problem behaviors consisted of SIB and disruptions. It was also reported that Tom occasionally engaged in property destruction, elopement, and aggression. Assessments showed Tom displayed relative strengths in the areas of tacting, listener skills, imitation, echoic, linguistics, visualperceptual, and reading. 


\section{Dependent Variables and Response Measurement}

Problem Behavior. We collected frequency data, which we converted to rate (i.e., responses per minute or RPM), as well as latency data (seconds).

The target behavior for Craig was aggression, which included hitting, headbutting, scratching, pinching, biting, pushing, hair-pulling, propelling objects toward, spitting in the direction of, or poking the eye of another individual. The target behavior for Ron was aggression, which included hitting, kicking, scratching, pinching, shoving, hair pulling, and throwing objects in the direction of another person. The target behavior for Tom was disruptions, which included yelling, screaming, and crying, as well as (SIB), which included hand-to-head, self-biting, and head banging.

FCR. Four topographically different FCRs were taught to each participant. Participants were taught to exchange a communication card, press a button on a speechgenerated device (SGD), emit an American Sign Language (ASL) response, and emit a vocal response. We collected frequency data and converted it to a rate measure in the form RPM. Each participants FCR responses are outlined in Table 1.

Table 1

FCR Description Across Participants

Exchange

Communication Button Press on

\begin{tabular}{lllll} 
Participant & \multicolumn{1}{c}{ Card Exchange } & \multicolumn{1}{c}{ a SGD } & \multicolumn{1}{c}{ ASL } & \multicolumn{1}{c}{ Vocal } \\
\hline Craig & $\begin{array}{l}\text { Laminated card } \\
\text { with the words, }\end{array}$ & Button press on & Sign "all & "Break time. \\
& "Break + Talk" & in a male voice & & Let's talk." \\
& $\begin{array}{l}\text { printed on the } \\
\text { center of the }\end{array}$ & saying, "Break & & \\
& time. Let's & & \\
& card. & talk." &
\end{tabular}

Ron Laminated card with the words, "Break + Play" printed on the

Button press on Sign "play" "Play, a SGD resulted please" in a male voice saying, "Break 
center of the time. Let's

card. Play."

Tom

Laminated card

with the word, "Play" printed on the center of the card.

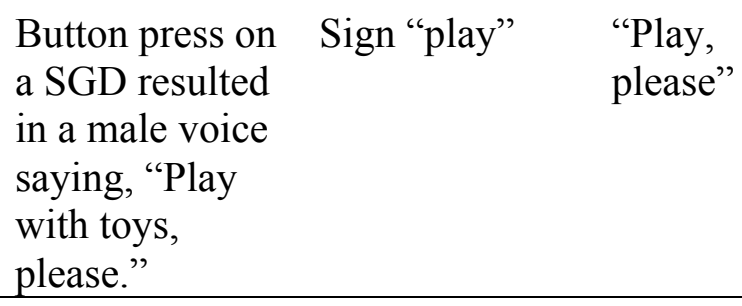

\section{Interobserver Agreement}

A second observer independently collected data for a total of $41 \%, 37 \%$, and $34 \%$ of sessions for Craig, Ron, and Tom, respectively. We calculated interobserver agreement (IOA) scores using the exact agreement method by dividing the session components into 10-s intervals for each active variable, calculating a proportion of agreement, dividing the sum of these proportions by the total number of intervals and converting the result to a percentage. An agreement was defined as both observers scoring the same behavior. For Craig, the mean IOA across all sessions was 99\% (range, 97\%-100\%). The mean agreement for problem behavior was $98 \%$ (range, $88 \%-100 \%$ ). Mean agreement for FCRs were 97\% (range, 82\%-100\%), 98\% (range, 88\%-100\%), 99\% (range, 90\%-100\%), and 99\% (range, 90\%-100\%) for FCR 1, FCR 2, FCR 3, and FCR 4, respectively. For Ron, the mean IOA across all sessions was 97\% (range, 91\%-100\%). The mean agreement for problem behavior was 99\% (range, 95\%-100\%). Mean agreement for FCRs were 98\% (range, 85\%-100\%), 98\% (range, 85\%-100\%), 97\% (range, 70\%-100\%), and 98\% (range, 75\%-100\%) for FCR 1, FCR 2, FCR 3, and FCR 4, respectively. For Tom, the mean IOA across all sessions was 98\% (range, $70 \%-100 \%$ ). The mean agreement for problem behavior was $98 \%$ (range, $70 \%-100 \%$ ). Mean agreement for 
FCRs were 99\% (range, 77\%-100\%), 99\% (range, 90\%-100\%), 98\% (range, 87\%-100\%), and 99\% (range, 95\%-100\%) for FCR 1, FCR 2, FCR 3, and FCR 4, respectively

\section{Procedural Fidelity}

We calculated procedural fidelity by dividing the session into 10 -s intervals and scoring either a correct or incorrect for each interval. A correct response was scored if all procedures outlined were implemented as intended. An incorrect response was scored if any portion of procedures outlined were not implemented as intended or if the therapist

failed to implement a component. A percentage was calculated by dividing the number of intervals with correct responses by the total number of intervals and multiplying by 100 .

Procedural fidelity was collected for $46 \%$ of Craig's sessions with an average of $98 \%$ procedural fidelity and a range of $85 \%$ to $100 \%$. Procedural fidelity was collected for $33 \%$ of Ron's sessions with an average of $97 \%$ procedural fidelity and a range of $87 \%$ to $100 \%$. Procedural fidelity was collected for $34 \%$ of Tom's sessions with an average of $94 \%$ procedural fidelity and a range of $80 \%$ to $100 \%$.

\section{Experimental Design}

During the functional analysis, we used a multi-element (Iwata et al., 1982/1994) or pair-wise experimental (Iwata et al., 1994) design. During the FCT evaluation we used a reversal design between four conditions: (a) baseline, (b) serial FCT (Lambert et al., 2017), (c) resurgence, and (d) FCT with lag schedule of reinforcement. The sequence for reversals was ABCBCADCDC. If either serial FCT or FCT with a lag schedule of reinforcement were ineffective, the conditions were not replicated. All sessions were 10min in duration. Because some FCRs were free operant responses (i.e., vocal mands and signs), all FCR materials were available during all sessions. We also evaluated if any of 
the FCRs were already in the response repertoire for any of the participants. An unreinforced control response (i.e., a black card) was also be available during all sessions in order to verify that the recovery of previously extinguished responses was response resurgence rather than the product of some other behavioral operation such as extinctioninduced variability (Lambert et al., 2017; Neuringer, Kornell, \& Olufs, 2001). After completion of this study, post extinction FCT and schedule thinning was conducted with all participants although these data were not be reported in this study.

\section{Procedures}

Functional Analysis. Functional analyses (Iwata et al., 1982/1994; Hanley et al., 2014) were conducted in order to determine the function of problem behavior. We conducted the procedures described by Iwata et al. (1982/1994) first. We conducted four conditions, attention, play (control condition), escape, and tangible conditions, in a multielement design. All sessions were 10-min in duration. During the attention condition, the session therapist provided the participant with 30 -s of pre-session access to high quality attention. At the start of the session, the therapist removed attention and delivered the statement, "I'm busy." The therapist provided attention contingent upon the target problem behavior (e.g., statement of concern or disapproval, physical attention such as a pat on the back, etc.). All other behaviors and requests for attention, including use of FCRs, were ignored. The play condition served as the control condition. In this condition, the participant had access to their highly preferred tangibles, no demands were presented, and the therapist provided attention on a FT 30-s schedule or whenever the participant bid for attention. There were no consequences for the target problem behavior. During the escape condition, the therapist presented continuous demands following the 
three-step guided compliance procedure. Three-step guided compliance consisted of the therapist first providing an instruction and waiting 5-s for the participant to respond. If they did not respond, the therapist provided the instruction and a model and waited 5-s for the participant to respond. If they did not respond, the therapist used physical guidance to prompt completion of the task. The therapist removed demands and provided access to a 30-s break contingent on the target problem behavior. All other behaviors and requests for a break, including FCRs, were ignored. In the tangible condition, the participant was provided with 30 -s of pre-session access to their highly preferred tangible item. The therapist removed the tangible item and delivered the statement, "It's mine." or, "You can't have it." The therapist delivered the tangible item for 30-s contingent on the target problem behavior. All other behaviors and requests for the tangible item, including use of the FCRs, were ignored.

We conducted the procedures described by Hanley et al. (2014) if the results of the first functional analysis were inconclusive. Before the analysis began, an open-ended interview was conducted to identify the type of contingencies that may influence problem behavior. The interview results were then used to design individualized and intimately matched test - control analyses that differed only in that the test condition included the putative reinforcement contingency and the control condition did not. Functional analyses involved alternating between a test and a control condition. During each control condition, which was always conducted first, the putative reinforcers were available throughout the session. During each test condition, the putative reinforcers were removed and were only returned contingent on the target problem behavior. All sessions were 10min in duration. 
Baseline. During baseline, the reinforcer maintaining problem behavior was delivered contingent on the target problem behavior. All FCR materials were present but did not result in reinforcement. We ended this phase after stability or an increasing trend in problem behavior.

Serial FCT. Participants were taught to exchange a communication card, press a button on a SGD, emit an ASL response, and emit a vocal response (Lambert et al., 2017). Procedures are summarized in Table 2. A picture prompt for the ASL response and a script for the vocal response were provided. We randomized the order of training of the four FCRs across participants and FCRs were reinforced on an FR1 schedule. The order of training for FCRs for each participant is summarized in Table 3.

During the first session for each FCR condition, the experimenter provided the participant with a contingency review and immediately prompted the FCR using a full physical prompt (hand-over-hand) after each presentation of an establishing operation (EO). A separate, prompt therapist provided a vocal prompt on a FT 15-s schedule for all subsequent sessions. If the participant engaged in an incorrect FCR, the prompt therapist provided error correction in the form of a vocal prompt to engage in the correct FCR.

An FCR was considered mastered when the participant independently engaged in the FCR response for $90 \%$ of opportunities and problem behavior was at or below 0.2 responses per minute (RPM) across three consecutive sessions. Independent FCRs were defined as any occurrence of the participant engaging in the FCR without the use of physical guidance and before a prompt has been delivered or when five seconds or more had elapsed since a vocal prompt had been delivered. A prompted FCR was defined as any occurrence of the participant engaging in the FCR with a full physical prompt or 
within five seconds of a verbal prompt. The percentage of independent FCRs was calculated by taking the RPM of independent FCRs divided by the sum of independent and prompted FCRs.

Table 2

Procedures for Training Multiple FCRs During the Serial FCT Condition

Topography Procedure

Exchange Communicative Card $\quad \mathrm{PBx} \rightarrow$ Extinction

FCR $1 \rightarrow \mathrm{S}^{\mathrm{r}}+$

Button Press on SGD $\quad \mathrm{PBx} \rightarrow$ Extinction

FCR $1 \rightarrow$ Extinction

FCR $2 \rightarrow \mathrm{S}^{\mathrm{r}}+$

ASL

$\mathrm{PBx} \rightarrow$ Extinction

FCR $1 \rightarrow$ Extinction

FCR $2 \rightarrow$ Extinction

FCR $3 \rightarrow \mathrm{S}^{\mathrm{r}}+$

Vocal

$\mathrm{PBx} \rightarrow$ Extinction

FCR $1 \rightarrow$ Extinction

FCR $2 \rightarrow$ Extinction

FCR $3 \rightarrow$ Extinction

FCR $4 \rightarrow \mathrm{S}^{\mathrm{r}}+$

Note. Topography order was randomized across participants. $\mathrm{PBx}=$ problem behavior; $\mathrm{S}^{\mathrm{r}}+=$ reinforcement

Table 3

Order of FCR Training Across Participants

\begin{tabular}{llll} 
FCR & Craig & Ron & Tom \\
\hline FCR 1 & $\begin{array}{l}\text { Exchange Communication } \\
\text { card }\end{array}$ & $\begin{array}{l}\text { Exchange Communication } \\
\text { card }\end{array}$ & ASL
\end{tabular}

FCR 2 Button press on SGD

ASL

Exchange Communication

Card

FCR 3 ASL

Button press on SGD

Vocal

FCR 4 Vocal

Vocal

Button Press on SGD 
FCT with Lag Schedule of Reinforcement. We implemented a lag schedule of reinforcement for FCRs that had been previously taught during the serial FCT condition. The lag schedule of reinforcement required the participant to vary the use of the different FCRs throughout the session to gain access to the reinforcers. We implemented a lag-2 schedule of reinforcement. This schedule required the participant to emit an FCR that is different than the previous two FCRs that were emitted. For example, if the participant previously emitted an ASL response and a vocal response, the button press on the SGD and exchange of the communication card would be available for reinforcement. During the first session, the participant was given a contingency review and immediately prompted with a full physical prompt (hand-over-hand) to engage in an appropriate FCR after each presentation of an EO. A prompt therapist provided a vocal prompt on a FT 15$\mathrm{s}$ schedule for all subsequent sessions. If the participant engaged in an incorrect FCR, the prompt therapist provided error correction in the form of a vocal prompt to engage in an FCR that was available for reinforcement. Mastery of FCT with lag schedule reinforcement condition was identical to that of the serial FCT condition.

Resurgence. All responses (target problem behavior and FCRs) were placed on extinction until stability of data is established. Due to the counter-therapeutic nature of the condition, we did not conduct more than ten sessions in any one resurgence phase for any participant. Therapeutic contingencies were reinstated following resurgence.

\section{Results}

Figure 1 shows the results of the functional analysis for Craig. We used the procedures outlined by Hanley et al. (2014). Following the open-ended interview and direct observations, it was hypothesized that escape from demands to access attention 
was likely the function of problem behavior. With this information, two conditions were developed. In the control condition, the therapist did not present any demands and Craig had access to high-quality therapist attention (i.e., racing, handshakes, imaginary robot play). In the test condition, the therapist did not provide high-quality attention and presented demands. Demands were removed and attention was delivered contingent on the problem behavior. We observed 0 instances of problem behavior across the control conditions. We observed elevated levels of problem behavior, which was on an increasing trend in the test condition with a mean rate of 7.2 responses per minute (RPM) and a range of 0 to $14 \mathrm{RPM}$. The results of the assessment indicate that Craig's aggression was maintained by escape from demands to access attention.

Figure 2 shows the results of the FCT evaluation for Craig. We observed elevated levels of problem behavior, which was on an increasing trend, in the first baseline phase with a mean rate of 7.2 RPM. Additionally, Craig did not engage in any FCRs, suggesting that these responses were not in his repertoire. During serial FCT, Craig engaged in all of the FCRs at elevated levels while problem behavior was immediately reduced and maintained at zero or near zero levels. In the FCR 1 phase, the mean rate of FCRs and problem behavior was 4.2 and 0.06 , respectively. In the FCR 2 phase, the mean rate of FCRs and problem behavior was 7.7 and 0 , respectively. In the FCR 3 phase, the mean rate of FCRs and problem behavior was 6.5 and 0 , respectively. In the FCR 4 phase, the mean rate of FCRs and problem behavior was 9.7 and 0, respectively. During the resurgence phase following serial FCT, we observed resurgence of problem behavior with a mean rate of 0.16 but did not see persistence of FCRs. Craig only engaged in two FCRs, both ASL responses, across all of the sessions in the first resurgence phase. These 
results were not desired; therefore, the serial FCT phase was not replicated. In our return to baseline we, again, observed elevated levels of problem behavior on an increasing trend with a mean rate of 14.06. Craig engaged in low rates of FCRs with a mean rate of 0.02. When FCT with a lag-2 schedule of reinforcement was implemented, we observed problem behavior decrease to zero rates immediately. We observed elevated levels of responding for all of the FCRs. The mean rate for FCR 1, FCR 2, FCR 3, and FCR 4 was $1.5,2,2$, and 1.9 , respectively. During the following resurgence phase, we observed resurgence of problem behavior at higher rates than the previous resurgence phase with a mean rate of 0.7 . We observed low rates of FCRs with a total frequency of 4 vocal responses across all sessions in this phase. Craig also did not vary the use of FCRs in this phase. These results were not desired; therefore, this phase was not replicated.

Figure 3 shows a comparison of latency to problem behavior during the resurgence test following serial FCT and FCT with lag-2 schedule of reinforcement for Craig. The mean latency to problem behavior following serial FCT was $271 \mathrm{~s}$. The mean latency to problem behavior following the lag-2 schedule of reinforcement was $294 \mathrm{~s}$. However, more sessions were conducted in the resurgence phase following the lag-2 schedule of reinforcement due to variability in problem behavior. Therefore, we compared the four sessions of resurgence following serial FCT and the first four sessions of resurgence phase following FCT with a lag-2 schedule of reinforcement and found that the mean latency to problem behavior was $271 \mathrm{~s}$ and $96 \mathrm{~s}$, respectively. These data show that, initially, there was a much shorter latency to problem behavior in the resurgence phase following FCT with a lag-2 schedule of reinforcement. 
Figure 4 shows the mean percentage of response allocation during the resurgence phase following serial FCT and FCT with lag-2 schedules of reinforcement for Craig. In the resurgence phase following serial FCT, problem behavior occupied a mean of $80 \%$ of response allocation and FCRs occupied a mean of $20 \%$. In the resurgence phase following FCT with a lag-2 schedule of reinforcement, problem behavior occupied a mean of $93 \%$ of response allocation and FCRs a mean of $7 \%$.

Figure 5 shows the frequency of FCRs in the resurgence phases. Because the resurgence phase following serial FCT had only four sessions, we also evaluated the frequency of FCRs in the first four sessions of the resurgence phase following FCR with a lag-2 schedule of reinforcement. Craig engaged in two FCRs in the resurgence phase following serial FCT, four FCRs in the resurgence phase following FCT with a lag-2 schedule of reinforcement (all sessions), and three FCRs when the first four sessions of the resurgence phase following FCT with a lag-2 schedule of reinforcement was evaluated. While we did see more FCRs in the resurgence phase following FCT with a lag-2 schedule of reinforcement, they were not clinically significant. 


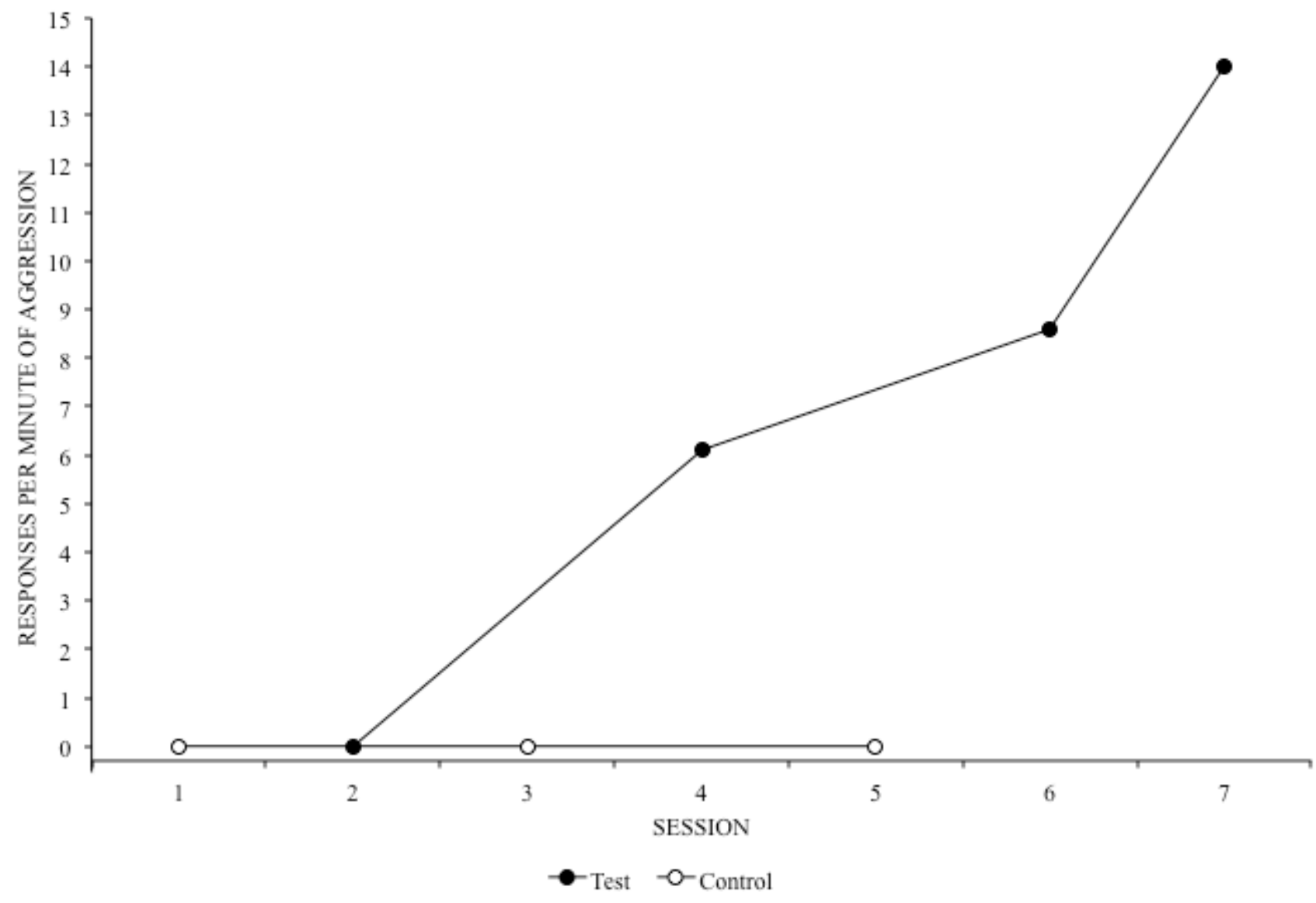

Figure 1. Results of the functional analysis for Craig depicting the responses per minute of problem behavior across test and control conditions 


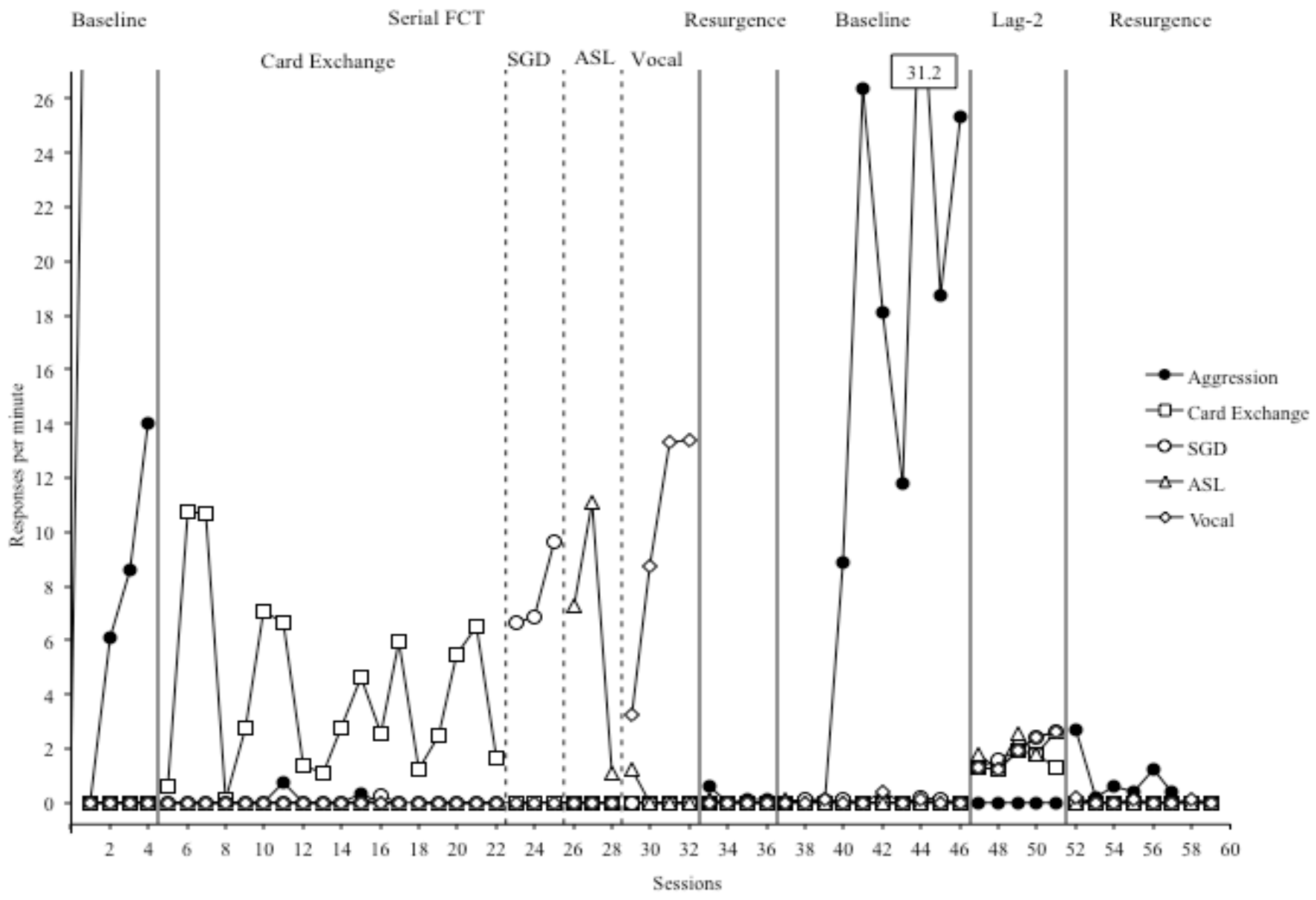

Figure 2. Responses per minute of problem behavior and FCRs for Craig. 


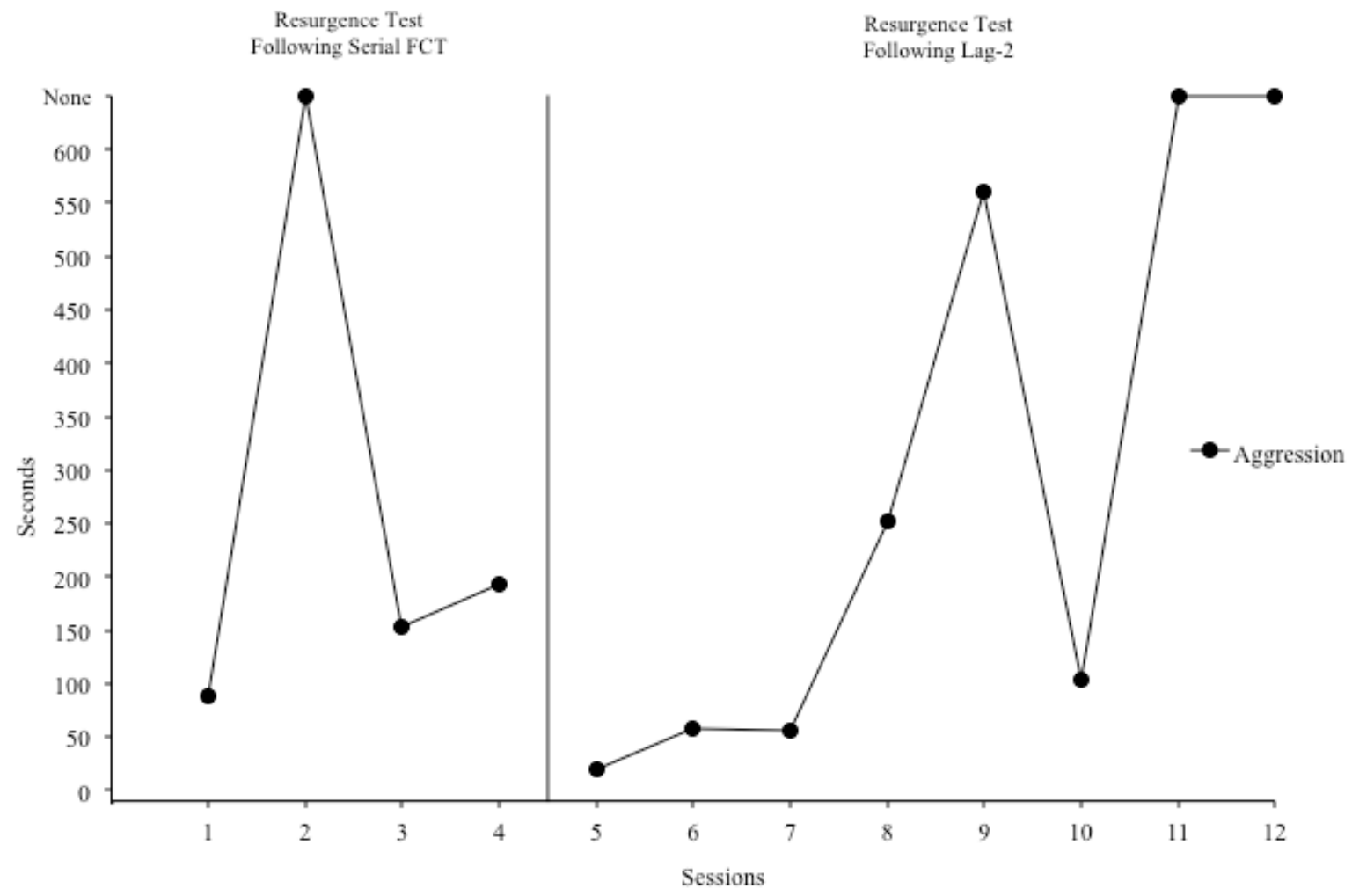

Figure 3. Latency to problem behavior during the resurgence phase following serial FCT and FCT with a lag-2 schedule of reinforcement for Craig. 


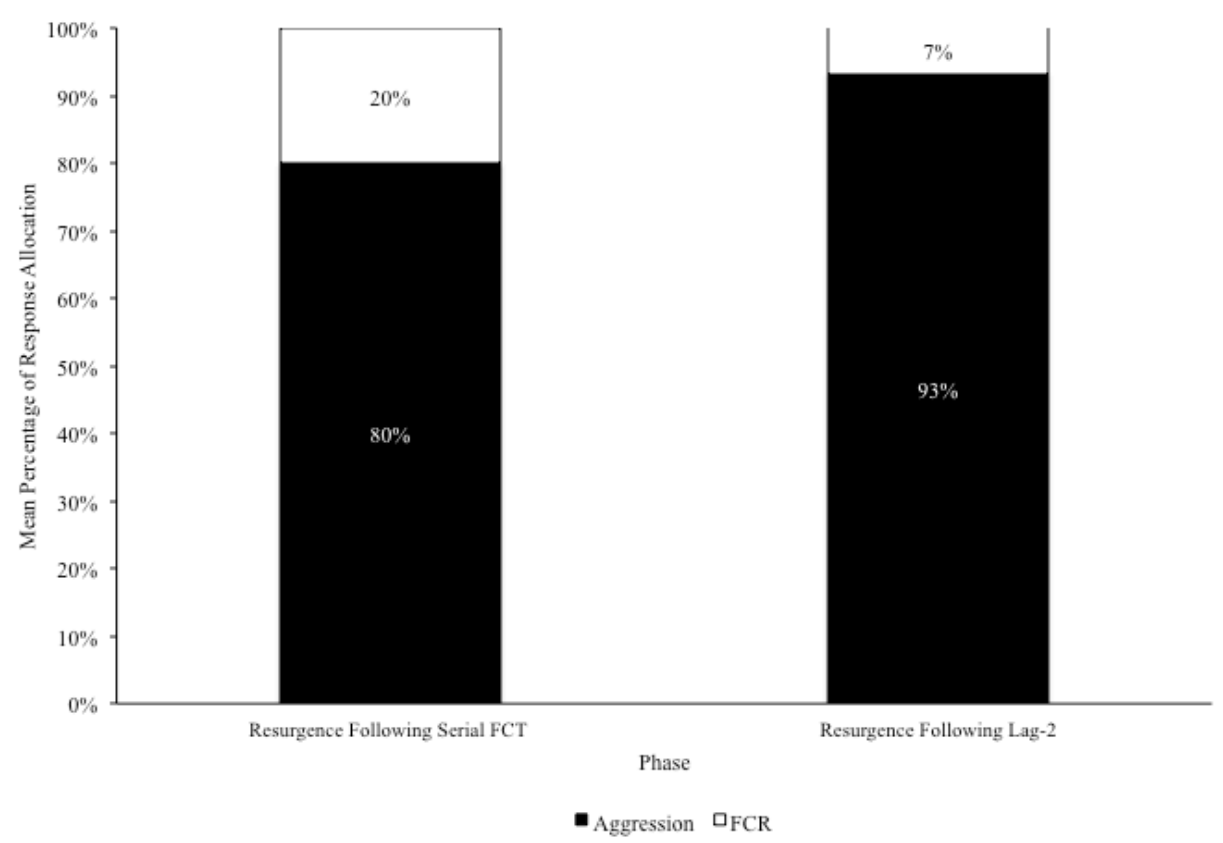

Figure 4. Mean percentage of response allocation for problem behavior and FCRs during the resurgence phase following serial FCT and FCT with a lag-2schedule of reinforcement for Craig. Black and white segments are stacked.

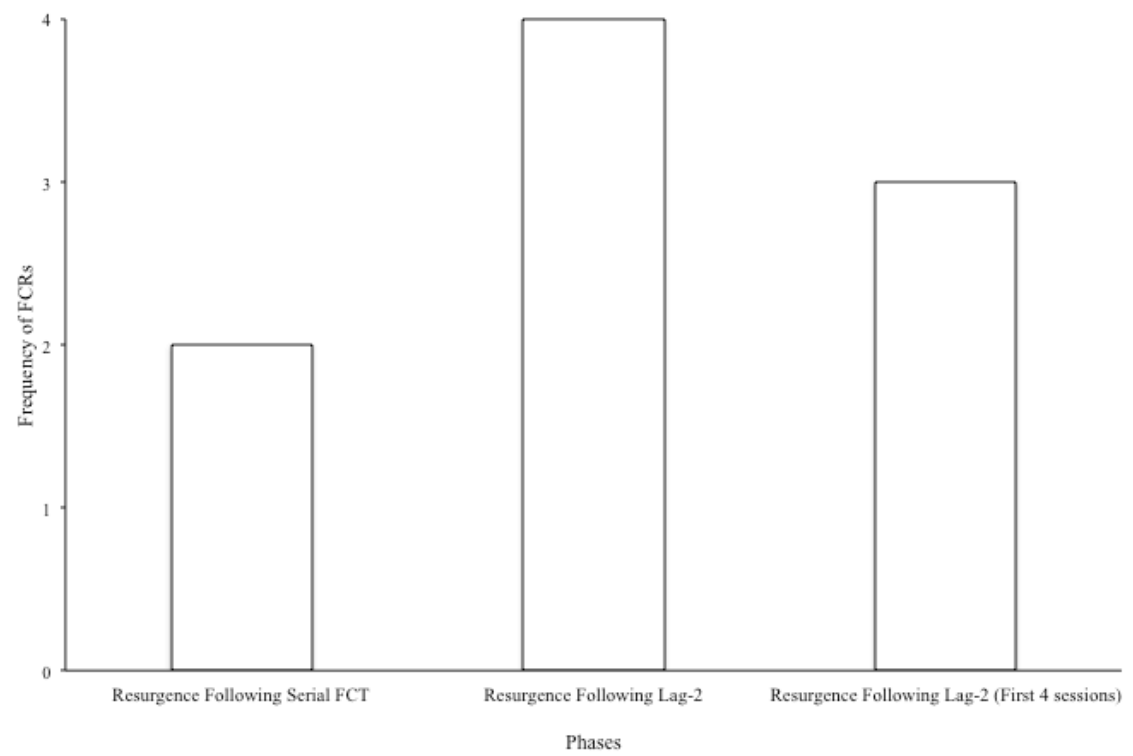

Figure 5. Frequency of FCRs in the resurgence phases following serial FCT, FCT with a lag-2 schedule of reinforcement, and the first four sessions following the lag-2 schedule of reinforcement for Craig. 
Figure 6 shows the results of the functional analysis for Ron. We used the procedures outlined by Hanley et al. (2014). Following the open-ended interview and direct observations, it was hypothesized that escape from demands to access tangibles was likely the function of the problem behavior. With this information, two conditions were developed. In the control condition, the therapist did not present any demands and Ron had access to highly preferred tangibles. In the test condition, the therapist removed access to tangibles and presented demands. Demands were removed and tangibles were delivered contingent on the problem behavior. We observed 0 instances of problem behavior across the control conditions. In the test condition, we observed elevated levels of problem behavior, which was on an increasing trend with a mean rate of 0.9 RPM and a range of 0.5 to $1.5 \mathrm{RPM}$. The results of the assessment indicate that Ron's aggression was maintained by escape from demands to access tangibles.

Figure 7 shows the results across all FCT phases for Ron. We observed elevated levels of problem behavior, which was on an increasing trend with a mean rate of 0.9 RPM Additionally, Ron did not engage in any FCRs, suggesting that these responses were not in his repertoire. During serial FCT, Ron engaged in all of the FCRs at elevated levels while problem behavior was immediately reduced and maintained at zero or near zero levels. In the FCR 1 (card exchange) phase, the mean rate of FCRs and problem behavior was 3.2 and 0.2 , respectively. In the FCR 2 (ASL) phase, the mean rate of FCRs and problem behavior was 3.6 and 0.2 , respectively. In the FCR 3 (SGD) phase, the mean rate of FCRs and problem behavior was 12.2 and 0 , respectively. In the FCR 4 phase, the mean rate of FCRs and problem behavior was 3.6 and 0 , respectively. During the resurgence phase following serial FCT, we did not observe resurgence of problem 
behavior. However, we also did not see persistence of FCRs. Ron engaged in a total frequency of four FCRs in the first resurgence session, all of which were vocal responses. Ron did not engage in any FCRs in the subsequent sessions. These results were not desired; therefore, the serial FCT phase was not replicated. In our return to baseline we observed initially low levels of problem behavior before observing elevated levels of problem behavior. Problem behavior occurred at a mean rate of 0.3 . Ron engaged in low rates of FCRs with a mean rate of 0.03 . When FCT with a lag-2 schedule of reinforcement was implemented, we observed problem behavior decrease to zero rates immediately. Ron was consistently selecting the SGD but was not independently varying the use of FCRs. Data were collected on prompted responses but are not depicted on the graph. The mean rate of prompted FCRs under the lag-2 schedule of reinforcement was 1.0. Due to a lack of varying the use of the FCRs, we conducted two consecutive training sessions in which an immediate prompt was provided to engage in an FCR that met the lag-2 schedule of reinforcement requirement. We also modified the error correction procedure to error blocking and redirection. Ron still did not independently vary the use of FCRs with these modifications. The mean rate of prompted FCRs under the lag-2 schedule of reinforcement with the error blocking procedure was 1.0. Ron was still consistently pressing the button press on the SGD but was not independently varying the use of the FCRs. The SGD was removed at session 105 in an attempt to shift responding to the other FCRs available. Initially, we saw some independent variability in responding when the button was removed before seeing a shift in responding and consistent use of the ASL response. The schedule of reinforcement was changed to a lag- 1 . We continued to see a lack of independent varied use of the FCRs under this schedule of reinforcement. 
The mean rate of prompted FCRs was 0.8 . After making the aforementioned modifications and no signs of progression of varied independent use of FCRs, Ron was removed as a participant from this study. Ron's problem behavior was addressed clinically but is not reported here.

Figure 8 shows latency to problem behavior during the resurgence test following serial FCT. Ron did not engage in problem behavior during the resurgence test. Ron did not master FCT with a lag schedule of reinforcement therefore there are no data to display for latency to problem behavior following FCT with a lag schedule or reinforcement

Figure 9 shows the mean percentage of response allocation during the resurgence phase following serial FCT; problem behavior occupied $0 \%$ of responding and FCRs occupied $100 \%$ of responding. There are no data to display for mean percentage of response allocation following FCT with a lag schedule of reinforcement.

Figure 10 shows the frequency of FCRs in the resurgence phase following serial FCT. Ron engaged in four FCRs, all of which were vocal FCRs in the first session. There are no data to display for the frequency of FCRs following FCT with a lag schedule of reinforcement. 


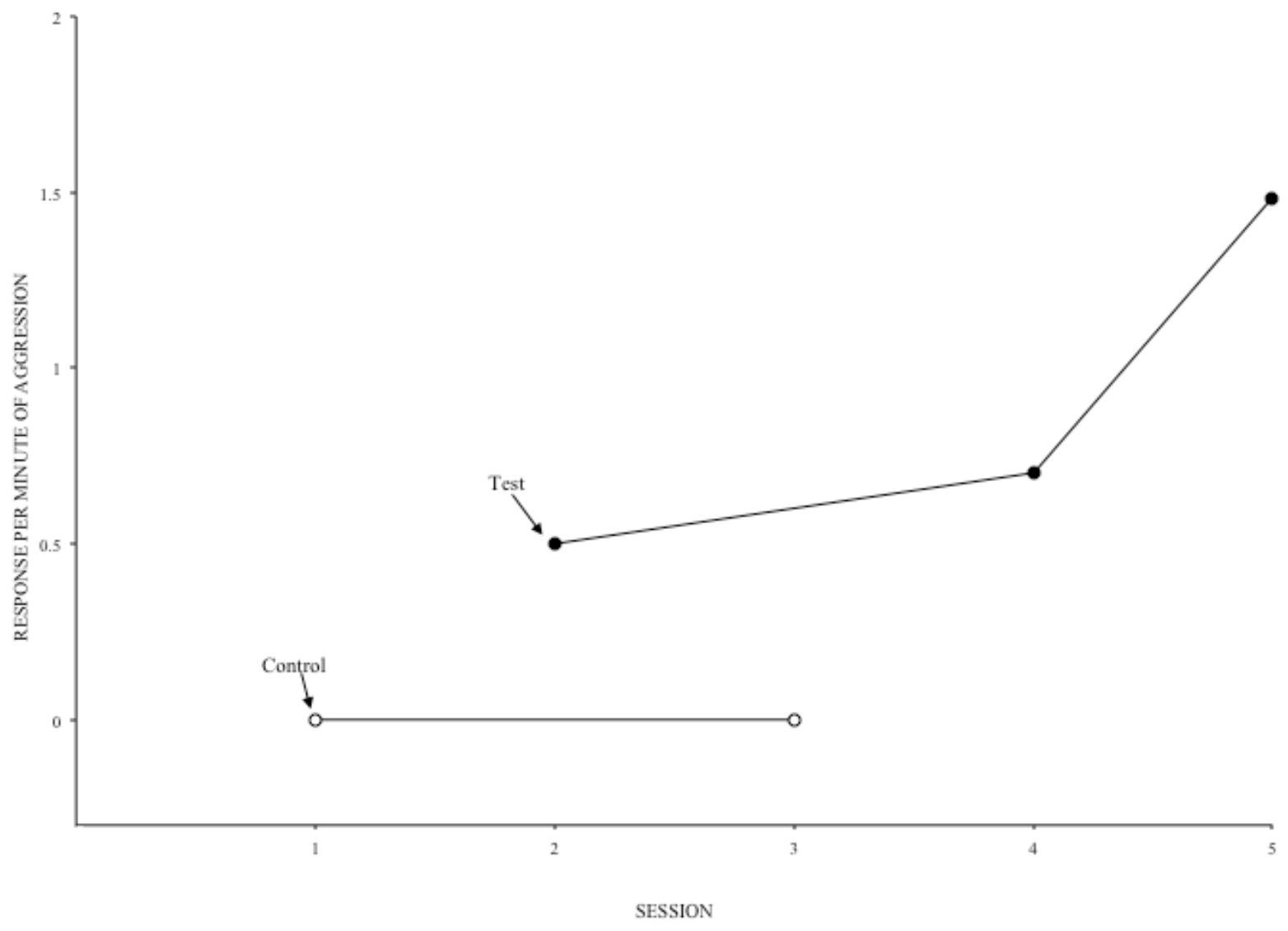

Figure 6. Results of the functional analysis for Ron depicting the responses per minute of problem behavior across test and control conditions. 


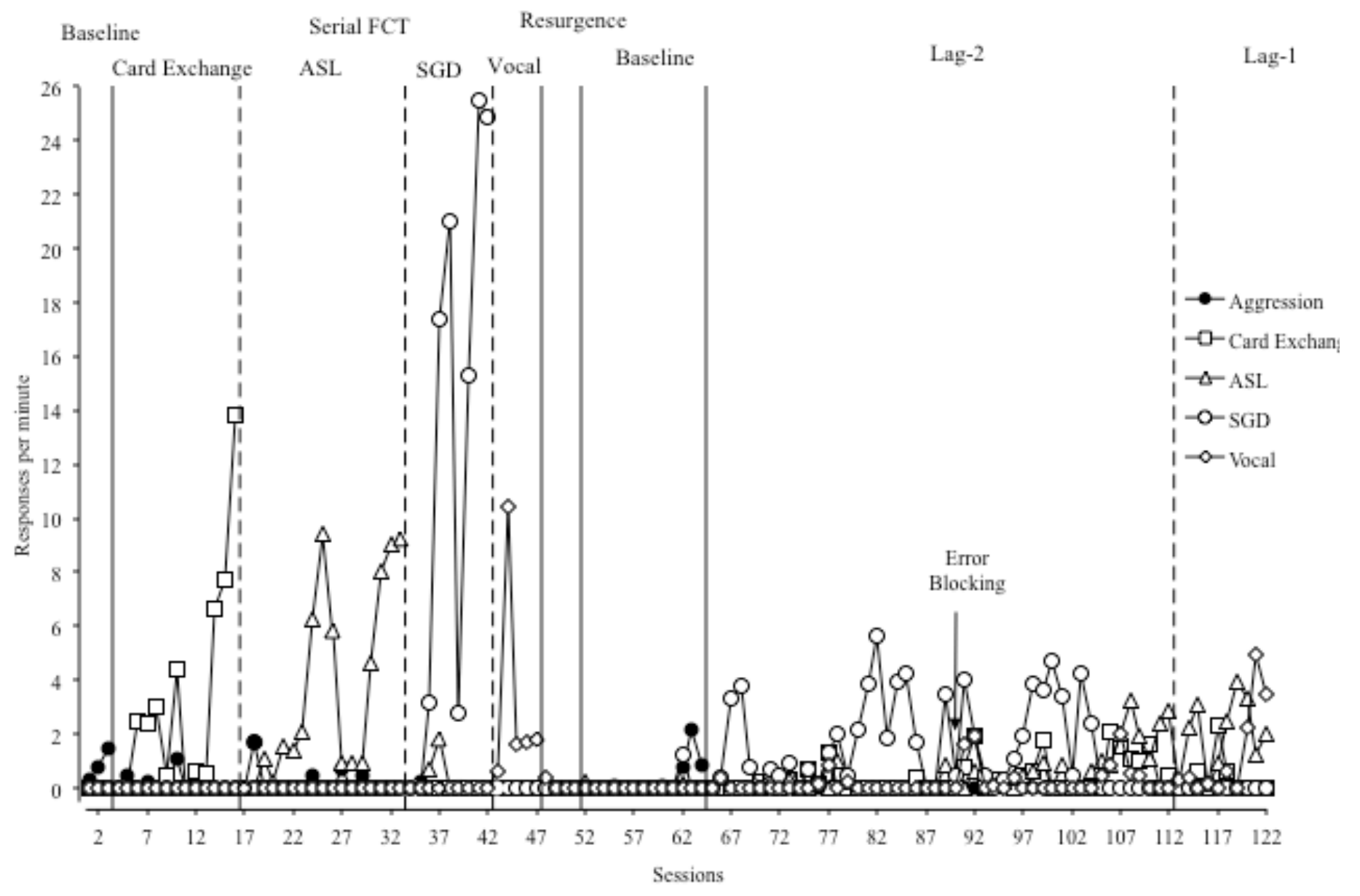

Figure 7. Responses per minute of problem behavior and FCRs for Ron. 


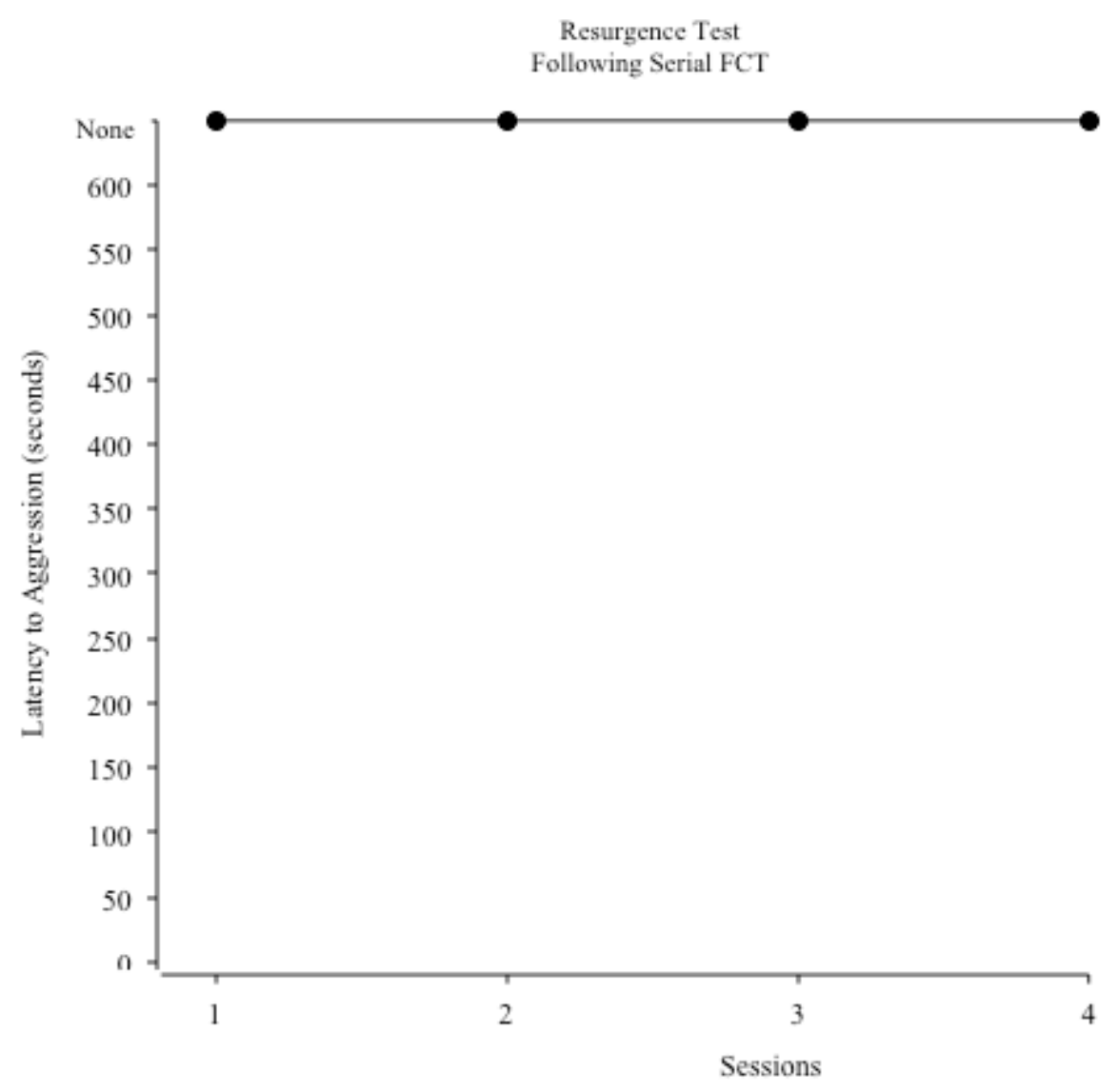

Aggression

Figure 8. Latency to problem behavior in the resurgence phase following serial FCT for Ron. 


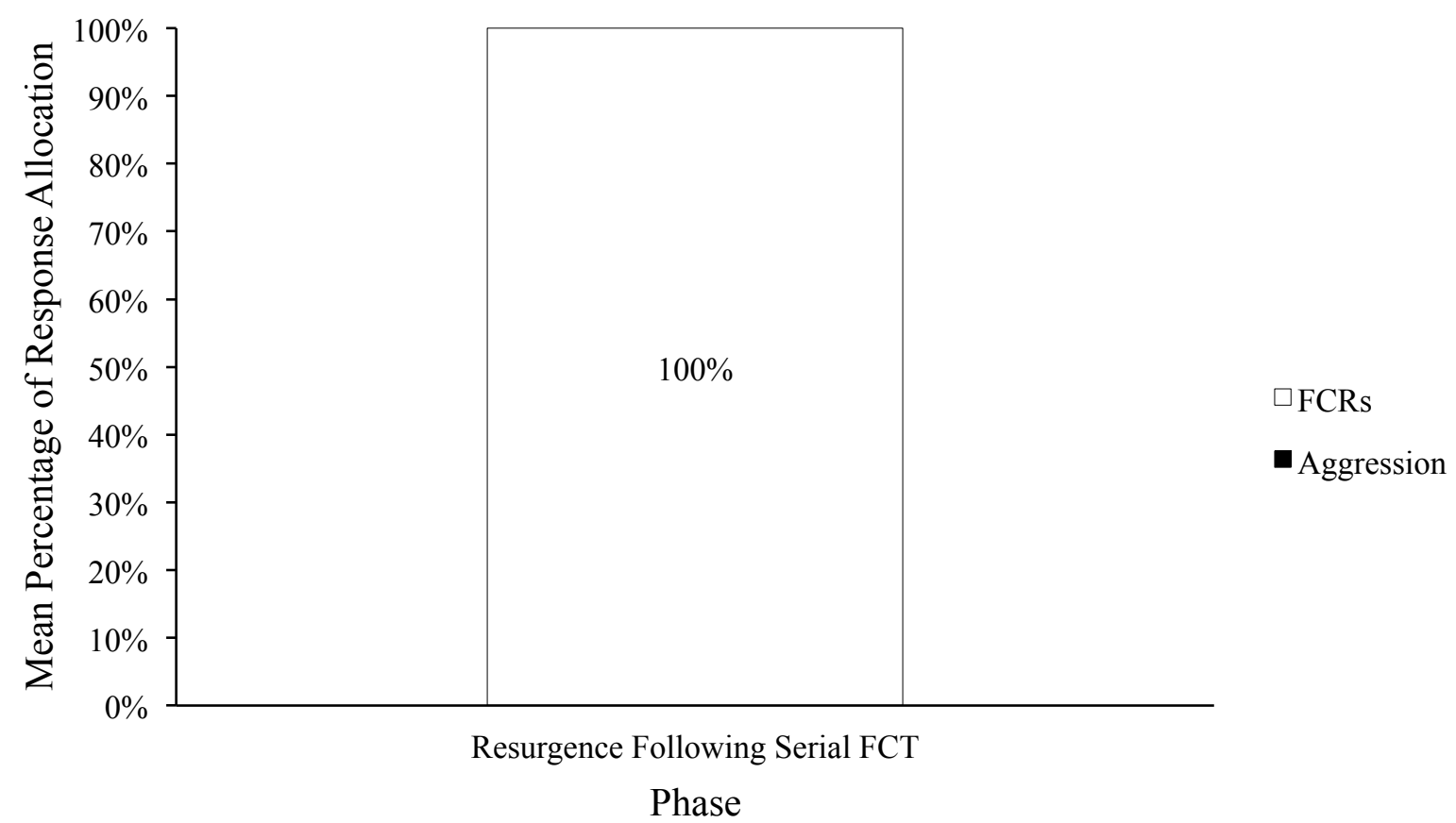

Figure 9. Mean percentage of response allocation for problem behavior and FCRs during the resurgence phase following serial FCT for Ron. Black and white segments are stacked 


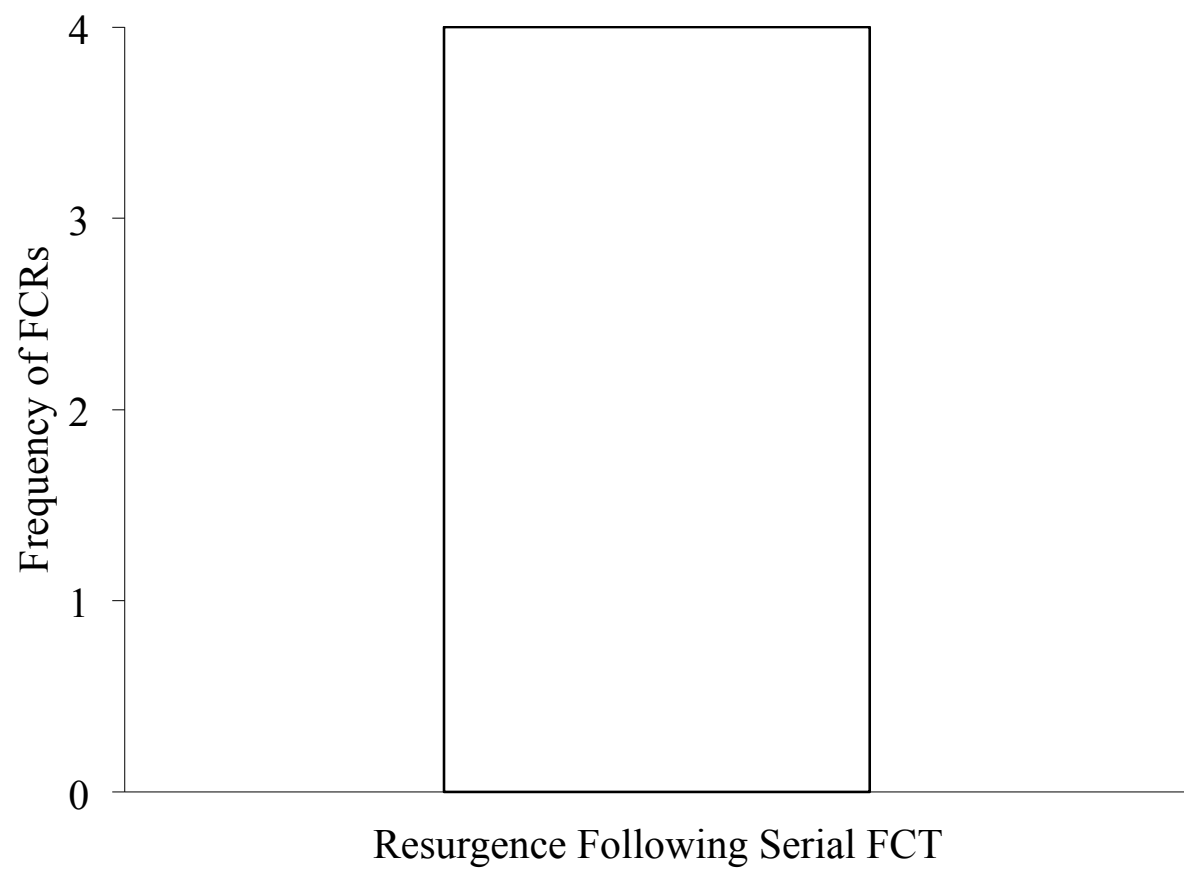

Phase

Figure 10. Frequency of FCRs in the resurgence phase following serial FCT for Ron. 
Figure 11 shows the results of the functional analysis for Tom. We used the procedures outlined by Iwata et al. (1982/1994). We observed 0 instances of problem behavior in both the play (control) condition and the attention condition. Responding in the tangible condition was elevated relative to the play (control) condition with a mean rate of responding of 1.8 and a range of 1 to 2.3. Based on these data, it was determined that disruptions and SIB were maintained by access to tangibles. The mean rate of problem behavior in the escape condition was 0.7 with a range from 0 to 1.8 ; however, there was variability in the responding. Due to the variability of these data and the last session decreasing to 0 , further assessment was conducted which confirmed the presence of an escape function. The escape function was treated clinically but not reported as a part of the present study.

Figure 12 shows the results across FCT phases for Tom. We observed elevated levels of problem behavior in the first baseline phase with a mean rate of 1.8 RPM. Tom engaged in FCR 3 (vocal) at low rates in baseline. Tom did not engage in any other FCRs, suggesting that these responses were not in his repertoire. During serial FCT, Tom engaged in all of the FCRs at elevated levels while problem behavior was immediately reduced and maintained at zero or near zero levels. In the FCR 1 (ASL) phase, the mean rate of FCRs and problem behavior was 4.9 and 0.09 , respectively. In the FCR 2 (card exchange) phase, the mean rate of FCRs and problem behavior was 4.6 and 0 , respectively. In the FCR 3 (vocal) phase, the mean rate of FCRs and problem behavior was 10.6 and 0 , respectively. In the FCR 4 (SGD) phase, the mean rate of FCRs and problem behavior was 6.3 and 0 , respectively. During the resurgence phase following serial FCT, we observed resurgence of problem behavior with a mean rate of 2.7 but did 
not see persistence of FCRs at stable elevated levels. The mean rate of FCRs was 0.14 and FCRs were quickly extinguished. These results were not desired; therefore, the serial FCT phase was not replicated. In our return to baseline we, again, observed elevated levels of problem behavior on an increasing trend with a mean rate of 11 . Tom engaged in low rates of FCRs with a mean rate of 0.06 . When FCT with a lag-2 schedule of reinforcement was implemented, we observed problem behavior decrease to zero rates immediately. We observed elevated levels of responding for all of the FCRs. The mean rate for FCR 1 (ASL), FCR 2 (card exchange), FCR 3 (vocal), and FCR 4 (SGD) was 0.3, $0.8,1.8$, and 1.2, respectively. Initially, Tom was not able to master FCT with a lag-2 schedule of reinforcement. Tom was showing a preference for the vocal response and requiring prompts from the therapist to engage in other FCRs. Additional training sessions with 0s (immediate) prompts were conducted before returning back to the FT$15 \mathrm{~s}$ prompt with an immediate error correction procedure. Tom again showed preference for the vocal response. Additional training sessions with 0s (immediate) prompts were conducted. Following the training sessions, prompting and error correction was on a FT$15 \mathrm{~s}$ schedule. This allowed Tom the opportunity to independently select another FCR when an error was emitted. Tom was able to master this phase following the implementation of the delayed error correction procedure. During the following resurgence phase, we observed resurgence of problem behavior with a mean rate of 1.55. We observed higher rates and more varied use of FCRs during resurgence following FCT with a lag-2 schedule of reinforcement. However, problem behavior occurred at consistently higher rates than FCRs. These results were not desired; therefore, this phase was not replicated. 
Figure 13 shows a comparison of latency to problem behavior during the resurgence test following serial FCT and FCT with lag-2 schedule of reinforcement for Tom. The mean latency to problem behavior following serial FCT was $119 \mathrm{~s}$. The mean latency to problem behavior following the lag-2 schedule of reinforcement was $334 \mathrm{~s}$. While the mean latency to problem behavior following the lag-2 schedule of reinforcement was longer, we observed comparable latencies to problem behavior in the first two sessions of each resurgence phase for Tom. The first and second resurgence sessions following serial FCT was $48 \mathrm{~s}$ and $10 \mathrm{~s}$ respectively. The first and second resurgence sessions following FCT with a lag-2 schedule of reinforcement was $26 \mathrm{~s}$ and 10 s respectively. Differences were observed in the last two sessions of each resurgence phase. Tom continued to engage in problem behavior in the last two sessions of the resurgence phase following serial FCT but did not engage in problem behavior during the last two sessions of the resurgence phase following FCT with a lag-2 schedule of reinforcement.

Figure 14 shows the mean percentage of response allocation during the resurgence phase following serial FCT and FCT with lag-2 schedules of reinforcement for Tom. In the resurgence phase following serial FCT, problem behavior occupied a mean of $82 \%$ of response allocation and FCRs occupied a mean of $18 \%$. In the resurgence phase following FCT with a lag-2 schedule of reinforcement, problem behavior occupied a mean of $57 \%$ of response allocation and FCRs a mean of $43 \%$. A significantly higher percentage of responding was allocated to the FCRs following the lag-2 schedule when compared to following serial FCT, however, problem behavior still occupied the highest percentage of responding. 
Figure 15 shows the frequency of FCRs in the resurgence phases. Tom engaged in 23 FCRs in the resurgence phase following serial FCT and 46 FCRs in the resurgence phase following FCT with a lag-2 schedule of reinforcement. While we observed a higher frequency of FCRs following the lag-2 schedule, it is important to note that problem behavior still occupied the highest percentage of response allocation as depicted in Figure 14. 


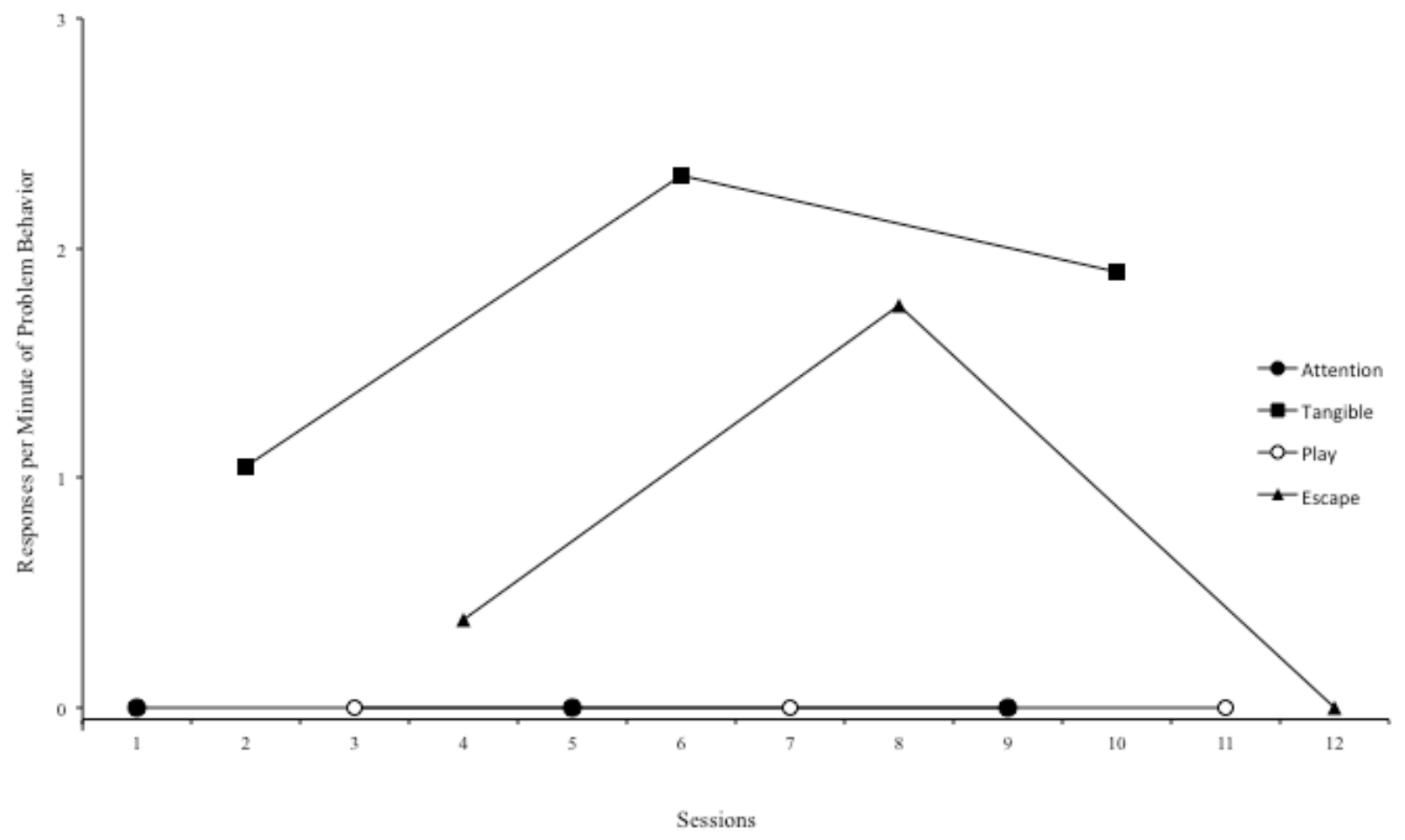

Figure 11. Results of the functional analysis for Tom depicting the responses per minute of problem behavior across conditions. 


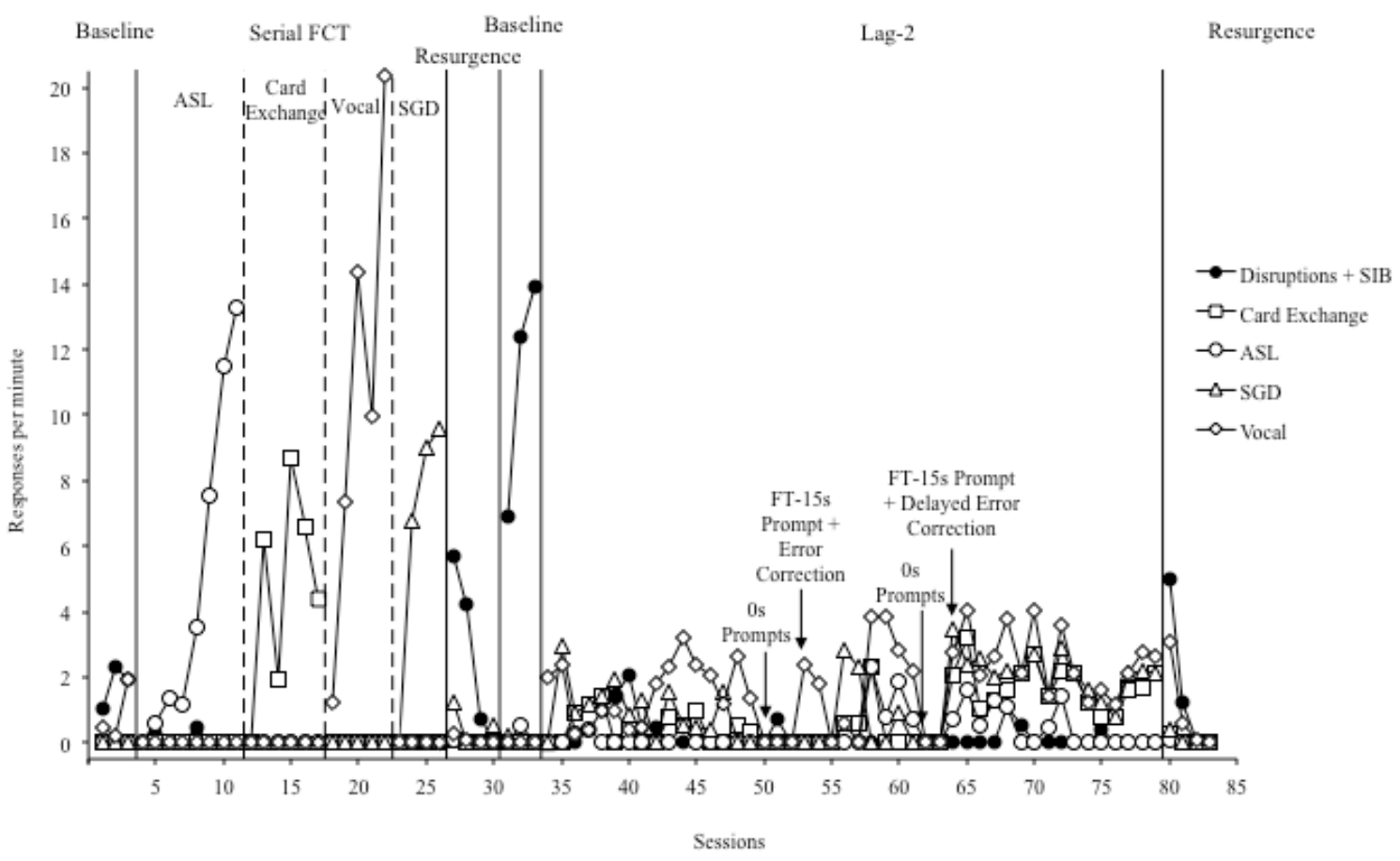

Figure 12. Responses per minute of problem behavior and FCRs for Tom 


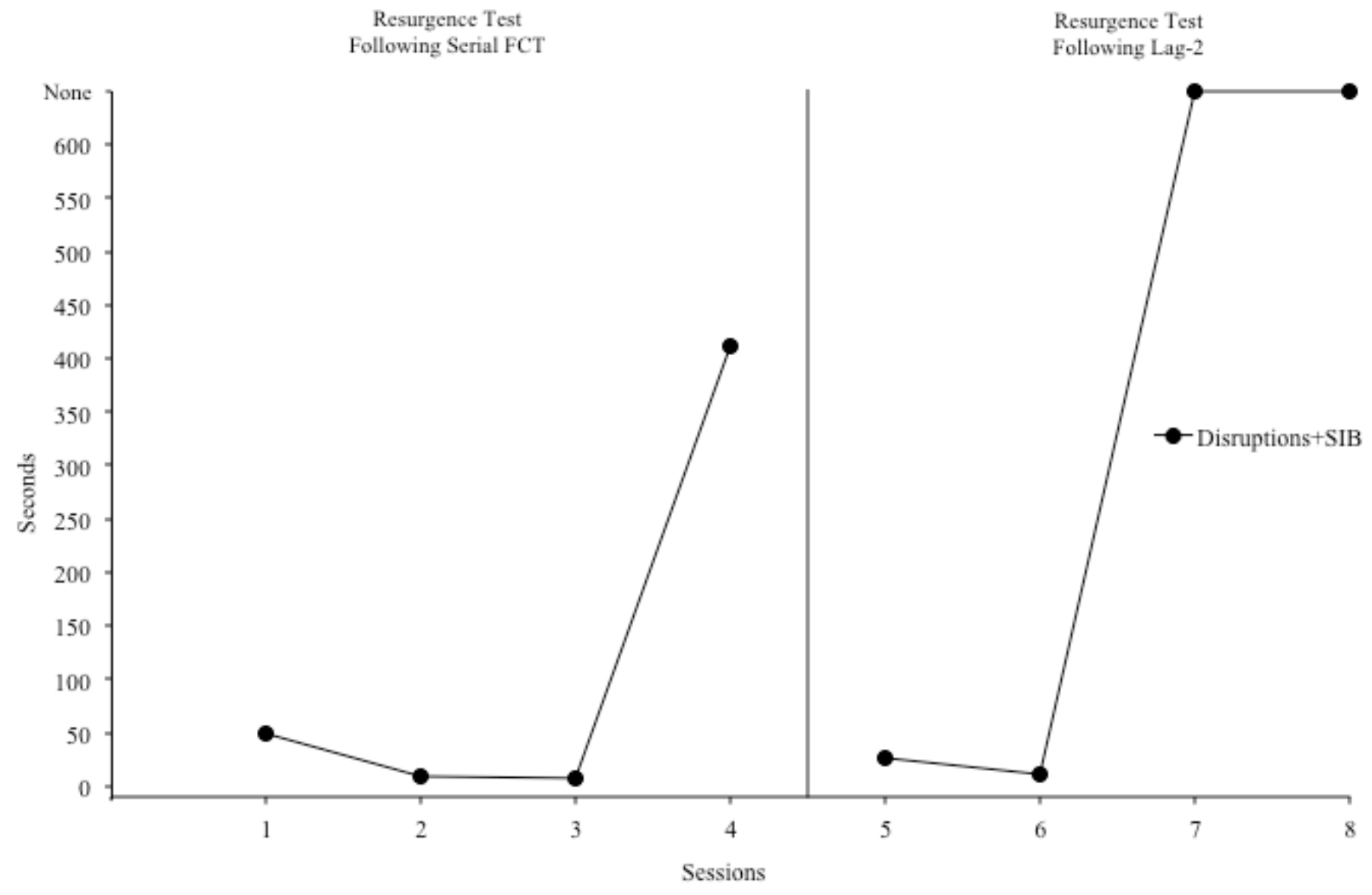

Figure 13. Latency to problem behavior during the resurgence phase following serial FCT and FCT with a lag-2 schedule of reinforcement for Tom 


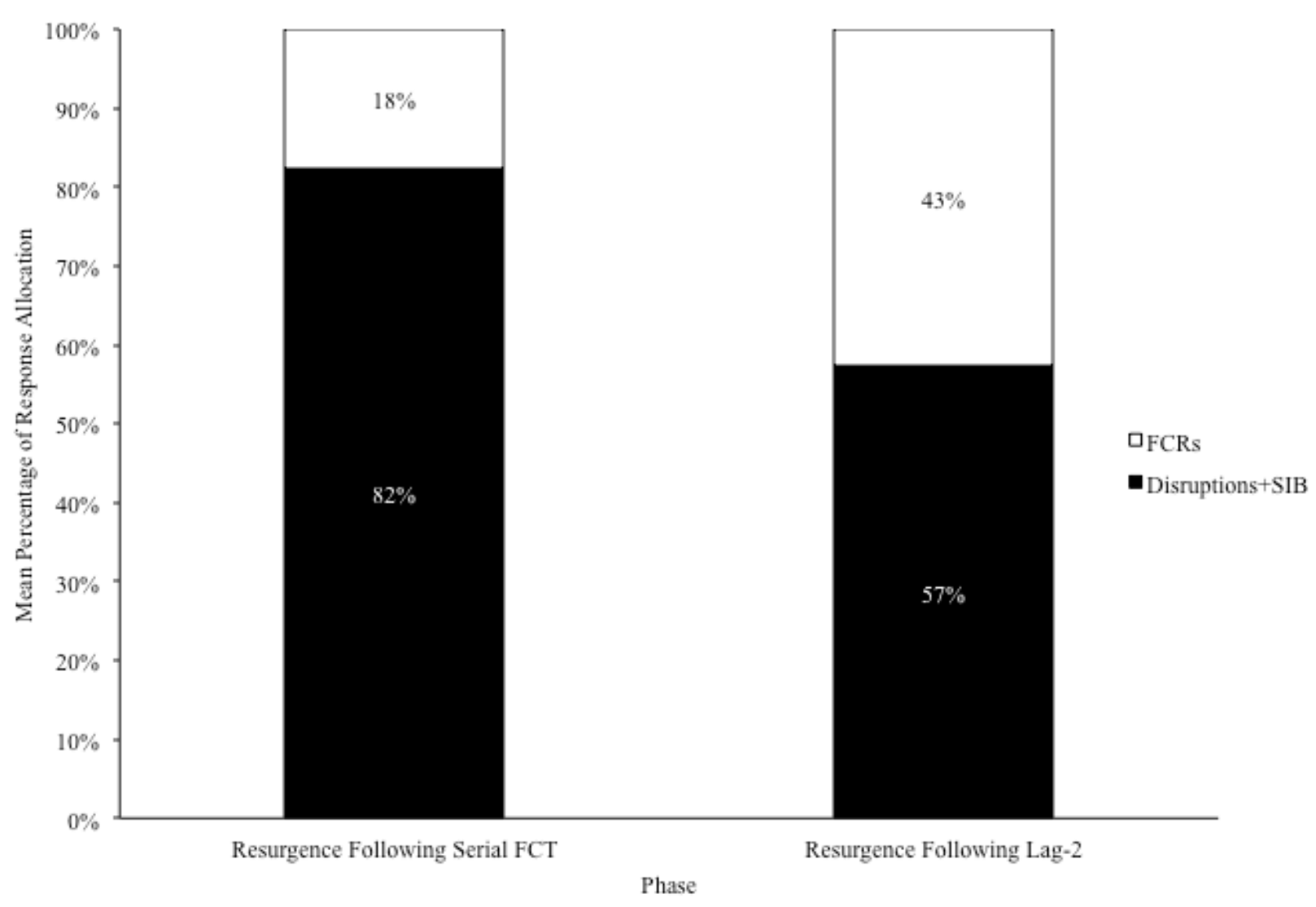

Figure 14. Mean percentage of response allocation for problem behavior and FCRs during the resurgence phase following serial FCT and FCT with a lag-2 schedule of reinforcement for Tom. Black and white segments are stacked. 


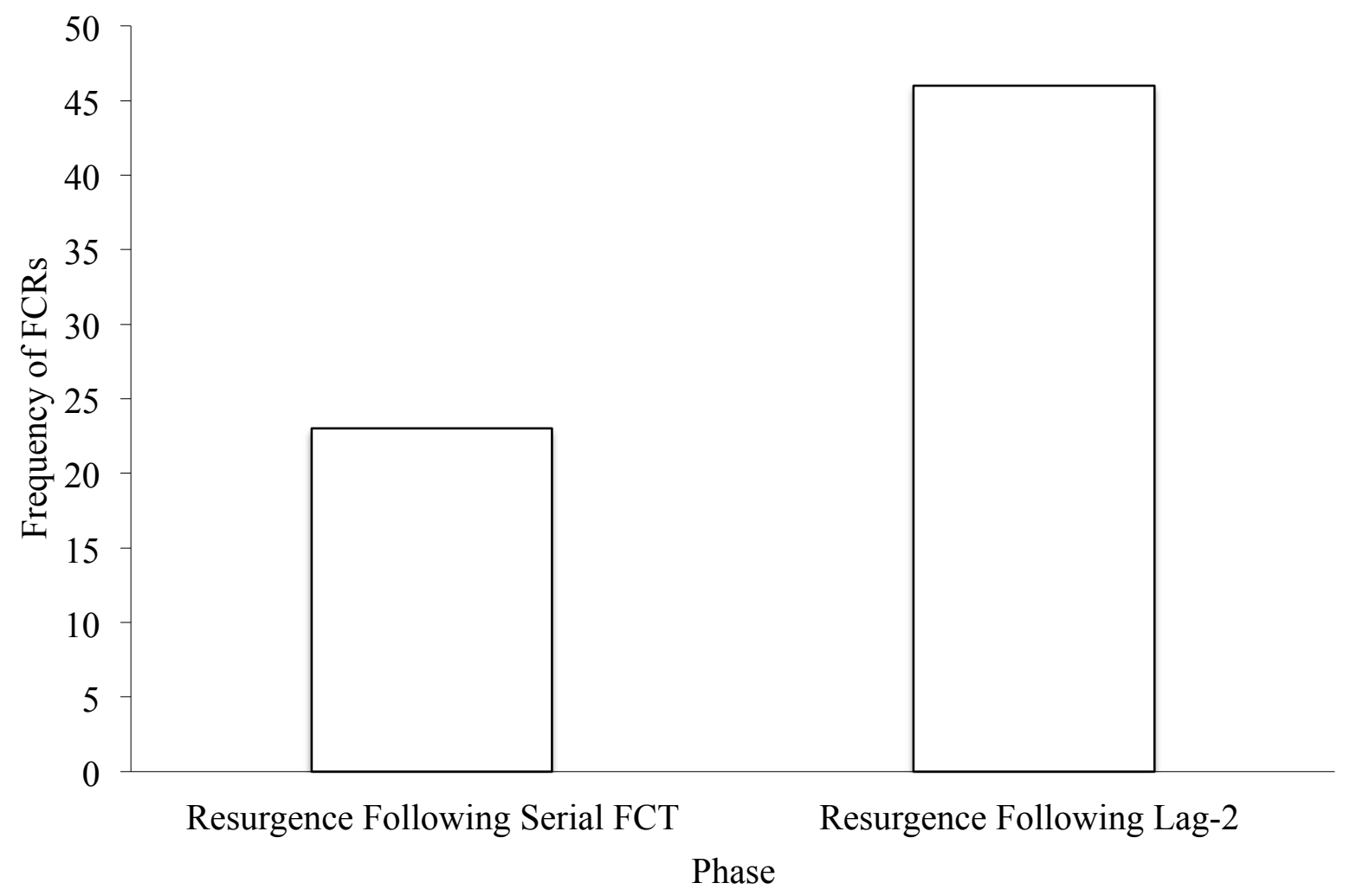

Figure 15. Frequency of FCRs in the resurgence phases following serial FCT and FCT with a lag- 2 schedule of reinforcement for Tom 


\section{Discussion}

The results of the present study indicate that teaching multiple FCRs in a serial FCT context is not sufficient to ensure the persistence of FCRs and significant delays or elimination of the resurgence of problem behavior during extinction challenges. These findings were consistent with the findings of Lambert et al. (2017) and suggest that further modifications are needed before it can be expected to produce outcomes that are more beneficial than what can be achieved through traditional FCT. This study extended the work of Lambert et al. (2017) by training multiple FCRs following serial FCT in the context of a lag-2 schedule of reinforcement in order to teach the participants to vary the use of FCRs and arrange for more rapid shifting contingencies. Implementing a lag-2 schedule of reinforcement produced some desired effects, such as a higher total frequency of FCRs; however, resurgence of problem behavior was observed at higher rates and short latencies. These findings suggest that further modifications are needed before it can be expected to produce desired outcomes beyond what can be achieved through traditional FCT.

While some desired effects were achieved following the implementation of a lag2 schedule of reinforcement, there were several limitations as well. First, one participant, Ron, never mastered FCT with a lag-2 schedule of reinforcement. Ron showed a high preference for the FCR, which required a button press on a SGD (i.e., consistently selecting the button as the first response). Procedures were modified in an attempt to teach Ron to vary the use of FCRs, including additional training sessions, implementing an error blocking procedure, and temporarily removing the SGD. When the device was removed, Ron consistently used the vocal response and did not vary the use of the FCRs. 
Despite these modifications, Ron never mastered the lag schedule and was removed as a participant of the study.

For one participant, Craig, we observed a higher percentage of response allocation to problem behavior over FCRs in resurgence following FCT with a lag-2 schedule of reinforcement relative to serial FCT. For the other participant, Tom, we observed a much higher percentage or response allocation to FCRs compared to Craig, however, problem behavior still occupied the largest percentage of response allocation. We also observed shorter latencies to problem behavior initially in resurgence following the lag-2 schedule of reinforcement for both Craig and Tom. While Tom initially had a shorter latency to problem behavior in the first session of resurgence following the lag schedule, the second session was nearly the same latency to problem behavior for both resurgence phases. Problem behavior persisted in the resurgence phase following serial FCT although at low rates while it was completely extinguished to zero in the resurgence phase following the lag schedule.

One desired effect that was observed for two of the participants in resurgence following the lag schedule was a higher frequency of FCRs. While Craig only had a moderate increase in the number of FCRs used, Tom's data show a large increase in the number of FCRs that were emitted in the resurgence phase. While Tom showed more persistence of emitting the FCRs, resurgence of problem behavior still occurred at higher rates.

It is important to note that the participants spent a relatively short amount of time exposed to the contingencies of the FCRs while problem behavior has likely been reinforced across a number of people and settings for a number of years before being 
referred and receiving behavioral services. It is possible that the differing reinforcement history may have impacted the results. Future research may want to prolong reinforcement of FCRs before conducting a resurgence test, which could increase the probability of seeing a greater persistence of FCRs and lower rates with longer latencies to problem behavior. It is also possible that varied rates of reinforcement within the different FCR topographies could have influenced responding. Future research could also potentially yoke the rate of reinforcement for each FCR.

A limitation to this study was purposefully placing appropriate responses on extinction. Given this concern, we did not conduct more than ten consecutive sessions of the resurgence test. None of the participants in the current study reached more than ten consecutive sessions of the resurgence test. If they had, the limit on the number of resurgence conditions could have impacted the results. Despite the limitation, extinction of appropriate responses in the resurgence test is a necessary component in order to evaluate the persistence of FCRs, effects on problem behavior, and resurgence. It is important to note that while this is a limitation, it is likely that appropriate responses are placed on extinction in the naturalistic environment.

One potential area of future research could be to examine implementing a more realistic resurgence test. For the purposes of this study, all responses (problem behavior and FCRs) were placed on extinction during resurgence. However, it is unlikely that these behaviors will face prolonged extinction in a naturalistic setting. It is much more likely that the behaviors occurring will be intermittently reinforced. It is possible that FCRs would have persisted and problem behavior could have remained low if there was intermittent reinforcement for FCRs. 
Another possible limitation to note is the possibility that some of the results were impacted by a sequencing effect. Problem behavior and FCRs contacted extinction in both phases and it is possible that extinction in one phase influenced the rate and/or pattern of the subsequent component.

More research is needed to determine the conditions under which persistence of FCRs will be observed during extinction challenges while maintaining low to zero rates of problem behavior resurgence. There are often many variables in the natural environment (i.e., busy schedule, multiple children to attend to, etc.) that may lead to lapses in procedural fidelity in which an appropriate FCR will be placed on extinction. This is a problem of social significance for which a solution has not yet been found. 


\section{References}

Carr, E. G., \& Durand, V. M. (1985). Reducing behavior problems through functional communication training. Journal of Applied Behavior Analysis, 18, 111-126. doi:10.1901/jaba.1985.18-111

Fisher, W. W., Piazza, C. C., Cataldo, M. F., Harrell, R., Jefferson, G., \& Conner, R. (1993). Functional communication training with and without extinction and punishment. Journal of Applied Behavior Analysis, 26, 23-36. doi:10.1901/jaba.1993.26-23

Hanley, G. P., Iwata, B. A., \& Thompson, R. H. (2001). Reinforcement schedule thinning following treatment with functional communication training. Journal of Applied Behavior Analysis, 34, 17-38. doi:10.1901/jaba.2001.34-17

Hanley, G. P., Jin, C. S., Vanselow, N. R., \& Hanratty, L. A. (2014). Producing meaningful improvements in problem behavior of children with autism via synthesized analyses and treatments. Journal of Applied Behavior Analysis, 47, 16-36. doi:10.1002/jaba.106

Iwata, B. A., Dorsey, M. F., Slifer, K. J., Bauman, K. E., \& Richman, G. S. (1994). Toward a functional analysis of self-injury. Journal of Applied Behavior Analysis, 27, 197-209. (Reprinted from Analysis and Intervention in Developmental Disabilities, 2, 3-20, 1982) doi:10.1901/jaba.1994.27-197

Iwata, B. A., Duncan, B. A., Zarcone, J. R., Lerman, D. C., \& Shore, B. A. (1994). A sequential, test- control methodology for conducting functional analyses of self-injurious behavior. Behavior Modification, 18, 289-306. https://doi.org/10.1177/01454455940183003

Kurtz, P. F., Boelter, E. W., Jarmolowicz, D. P., Chin, M. D., \& Hagopian, L. P. (2011). An analysis of functional communication training as an empirically supported treatment for 
problem behavior displayed by individuals with intellectual disabilities. Research in Developmental Disabilities, 32, 2935-2942. https://doi.org/10.1016/j.ridd.2011.05.009

Lambert, J. M., Bloom, S. E., Samaha, A. L., Dayton, E. (2017). Serial functional communication training: Extending serial DRA to mands and problem behavior. Behavioral Interventions, 32, 311-325. https://doi.org/10.1002/bin.1493

Lee, R., Sturmey, P., \& Fields, L. (2007). Schedule-induced and operant mechanisms that influence response variability: A review and implications for future investigations. The Psychological Record, 57, 429-455. http://dx.doi.org/10.1007/s10803-006-0080-7

Leitenberg, H., Rawson, R.A., \& Mulick, J.A. (1975). Extinction and reinforcement of alternative behavior. Journal of Comparative and Physiological Psychological Record, 88, 640-652. https://doi.org/10.1037/h0076418

Neuringer, A., Kornell, N., \& Olufs, M. (2001). Stability and variability in extinction. Journal of Experimental Psychology: Animal Behavior Processes, 27, 79-

94. http://dx.doi.org/10.1037/0097-7403.27.1.79

Rooker, G. W., Jessel, J., Kurtz, P. F., \& Hagopian, L. P. (2013). Functional communication training with and without alternative reinforcement and punishment: An analysis of 58 applications. Journal of Applied Behavior Analysis, 46, 708-722. http://doi:10.1002/jaba.76

Tiger, J. H., Hanley, G. P., \& Bruzek, J. (2008). Functional Communication Training: A Review and Practical Guide. Behavior Analysis in Practice, 1, 16-23. http://doi.org/10.1007/BF03391716 